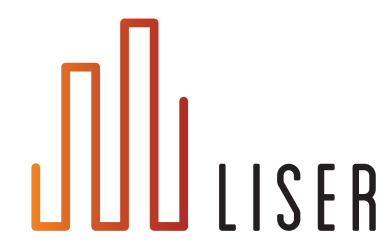

LUXEMBOURG InSIITUTE OF SOCIO-ECONOMIC RESEARCH

Choice op pension management fees and effects on pension wealth

Noelia BERNAL ${ }^{\mathbf{1 , 2}}$

Javier OLIVERA ${ }^{3,4,5}$ 
LISER Working Papers are intended to make research findings available and stimulate comments and discussion. They have been approved for circulation but are to be considered preliminary. They have not been edited and have not been subject to any peer review.

The views expressed in this paper are those of the author(s) and do not necessarily reflect views of LISER. Errors and omissions are the sole responsibility of the author(s). 


\title{
Choice of pension management fees and effects on pension wealth*
}

\author{
Noelia Bernal and Javier Olivera ${ }^{\dagger}$
}

January 2020

\begin{abstract}
To shed light on the effects of individual choice on pension wealth, we study a policy change to the management fees of pension funds implemented by Peru's government in 2013. The reform established a new balance fee as a default option; this fee is calculated as a percentage of the pension balance. Each individual had the initial option of keeping the previous management fee, a load factor fee calculated as a percentage of the individual's salary. We use administrative data to simulate pension balances based on the individual's choice of fee and the corresponding counterfactual. Our results indicate that the reform has been potentially adverse to 63.1 percent of individuals, of whom 41.4 percent were assigned to the default option and 21.7 percent voluntarily chose the load fee. These results reflect both the potentially negative unintended effects of the policy and an alarming lack of financial literacy among citizens. We also detect heterogeneity in the intensity of the losses and gains due to the reform, which caused greater losses than gains. In particular, younger and poorer individuals, as well as those automatically assigned to the balance fee, experienced higher losses. Moreover, the new fee scheme is also associated with increasing inequality between individuals' pension wealth.
\end{abstract}

Key words: Pension savings, management fees, individual retirement accounts, pension reform, inequality, Peru

JEL-classification: D31, G28, J14, J32.

*We are grateful to Nicolás Dominguéz, Daniel Castillo and Alfonso Rodríguez who contributed to the initial stage of the research. We also would like to thank Sander Muns and the participants of presentations held in Washington (LACEA Labor Network Meeting), Singapore, Paris, Lima and Leiden (Netspar) for their helpful comments. William Fernández provided excellent research assistance. We are also grateful to the Superintendency of Banking, Insurance and Pension Fund Managers for providing the administrative data. Declarations of interest: none.

${ }^{\dagger}$ Bernal: Universidad del Pacífico (UP) and Netspar; e-mail: n.bernall@up.edu.pe. Olivera (corresponding author): Luxembourg Institute of Socio-Economic Research (LISER), Pontificia Universidad Catolica del Peru (PUCP) and KU Leuven; e-mail: javier.olivera@ liser.lu. 


\section{Introduction}

Over time, proposals to transform old public pension systems into Individual Retirement Accounts (IRAs) have fueled much debate among both policymakers and academics. Latin America is an interesting case because it has experience an important wave of pension reform starting in 1981 with Chile and then moving to other countries (e.g., Peru 1992, Colombia 1993, Mexico 1997). Studies have reached some agreement on the positive spillover effects of these reforms, which include greater national savings, enhanced growth, and robust financial and annuity markets (Kritzer et al. (2011), Aguila et al. (2014)). This stream of research provides little knowledge of how management fees affect individual pension wealth. Indeed, the levels and applications of these fees vary considerably across countries and therefore may have different effects on the final value of pensions. Furthermore, high fees are a constant source of criticism in countries with mandatory IRA systems. Hence, gaining a better understanding of their effects is important. ${ }^{1}$

We use a 2013 change to the fee scheme of Peruvian IRAs to shed light on the potential longterm effects on individual pension wealth. Before the reform, individuals paid a load factor fee, which is calculated as a percentage of the monthly salary. The reform established a balance fee calculated as a percentage of the pension balance. Individuals had about five months to choose between the two fees. After this window, if individuals did nothing, they were assigned to the new balance fee (default option). The fee scheme, either chosen or assigned to the individual, is irreversible. Importantly, the balance fee is not applicable to the pension balance accrued before the reform; it applies only to the balances after the reform and is compulsory to all the new individuals enrolled since January 2013. Note that the balance fee scheme includes a temporary load factor fee that (by regulation) will gradually decrease down to zero by 2023 and a balance fee that will remain indefinitely.

Our analysis uses a sample of 64,588 individual administrative registers for those enrolled in the Peruvian IRA system as of December 2016. This data comes from the Superintendencia de Banca, Seguros y Administradoras Privadas de Fondos de Pensiones (known as SBS), a public institution that monitors and regulates the private pension system. We simulate the final value of the pension balance for each individual in our sample under certain assumptions and apply a series of sensitivity checks for key parameters. We use this sample to capture the heterogeneity of the population exposed to the policy change to management fees along with those individuals who actively opted out of the new balance fee. Importantly, we simulate and compare pension balances earned with the individual's choice of fee and the hypothetical balance in the corresponding counterfactual. Therefore, we are able to assess the losses or gains in savings due to the choice of fee.

Other studies analyze the effects of fees in compulsory IRA systems on pension wealth, such

\footnotetext{
${ }^{1}$ See Table A. 1 in the appendix for a description of IRA fees for selected countries and Table A.2 for details on the fee levels of Peruvian IRAs.
} 
as Whitehouse (2001), Alonso et al. (2014), Aguila et al. (2014) and Chávez-Bedoya (2017). In particular, Alonso et al. (2014) analyse some additional features of the Peruvian policy reform, which included various regulatory changes and not only the change in management fees. They use a representative agent model. However, they only compute the mechanical effect of the change in fees on the specific example of a 40-year-old worker. Chávez-Bedoya (2017) discusses the theoretical implications of both the density of pension contributions and risk aversion on the final level of individual pensions for different schemes of management fees. He illustrates his predictions with parameters of the Peruvian IRA system. Our work is different because we use observed and representative data of the individuals affected by the reform and exploit the heterogeneity in that population to observe results for different groups. ${ }^{2}$ Indeed, accounting for individual heterogeneity is important when studying pension reform, as the gaps between winners and losers can be considerable (see for example Gallo et al. (2018)). Importantly, we are also able to account for distributional concerns regarding the relationship between the individual's position in the income and pension wealth distribution and the potential gains or losses from the fee change. Aguila et al. (2014) study the Mexican IRA system that, prior to 2008, had three types of fees (load fee, balance fee and return rate fee), but then moved to only a load fee. They find that before 2008, the management fees significantly reduced pension wealth and increased claims for publicly subsidized minimum pensions. Dobronogov and Murthi (2005) analyse pensions in Croatia, Hungary, Kazakhstan and Poland and find that management fees (varying from 0.6 to 1.2 percent of assets) reduce the returns on an IRA by around 1 percent per year.

The balance fee of the Peruvian reform can have important consequences on the value of retirement wealth. Using data from a large Australian pension fund, Dobrescu et al. (2016) show that default settings strongly influence wealth accumulation and that poorly designed default options - particularly the irreversible ones - can severely affect retirement savings. Indeed, the broader literature has already examined the role of default settings causing sub-optimal retirement outcomes (e.g. Carroll et al. (2009), Goda and Flaherty (2013)).

Our results are in line with these findings, indicating that the policy reform is beneficial only for 36.9 percent of the people but adversely affects the other 63.1 percent. This last figure is composed of 41.4 percent of total individuals who were assigned to the balance fee, despite it being disadvantageous for them, and 21.7 percent who voluntary made the disadvantageous choice of choosing the load factor fee. This result therefore reveals both the negative unintended effects of a policy design and an alarming lack of soundness in many individuals' financial decisions. Furthermore, we find an important relationship between an individual's age and their optimal fee structure. The load factor fee seems quite a good option for the majority of young individuals (aged about 40 or below) because it does not reduce the pension wealth too much, whereas a balance fee charged to younger individuals (and therefore over a longer period

\footnotetext{
${ }^{2}$ Our analysis focuses on the individuals for whom the reform is salient, defined as those enrolled before 2013 who actively contribute.
} 
of capitalization) does. In contrast, the default fee may be better for older individuals as the capitalization period is shorter and therefore the reduction of overall wealth over time will be less dramatic. Unfortunately, the Government did not consider age when assigning the default fee, nor did they allow any possibility of opting out.

Our analytical data set composed of individual administrative records does not allow us to establish whether the individuals assigned to the balance fee were simply inactive about the fee choice or believed that the balance fee best served their interests. Regardless, it is worrying that most of them are worse off due to the reform. For those who opted for the load factor fee, is also worrying that almost one quarter were "wrong" about staying with this scheme.

Financial literacy is a key determinant of good decisions about investments, including pension funds. For example, Banks et al. (2015) and Hastings and Mitchell (2020) find that better financial knowledge would have helped individuals choose better annuities or accumulate more wealth. Although our data set does not include direct measures of financial literacy, we capture this feature by using a variable that measures how actively individuals manage their pension fund portfolios. The results suggest that financial literacy influences the quality of decisions made about pension fund fees. Unfortunately, in Peru, levels of financial literacy are quite low. The country ranked 97th out of 142 countries in the S\&P FinLit Survey conducted worldwide in 2014 (see Klapper et al. (2015)). This important limitation was not taken into account in the policy design.

Originally, the policy designed by the SBS was intended to apply the balance fee to all individuals, removing the load fee entirely, but the Parliament amended the reform and allowed the individuals choosing the load fee. However, given that the adopted fees are irreversible, the policy has inadvertently established a trap: potential reductions in the balance fees (relative to load fees) cannot be taken advantage of by the individuals who actively chose the load fee. When we simulate pension wealth by assuming larger reductions in the balance fees over time, the share of the reform's losers increases and more individuals who chose the load fee become losers.

We also detect large heterogeneity in the intensity of the losses and gains due to the reform. The losses tend to be larger than the gains; the average size of the change in the final pension balance for those who lose is -5.0 percent and 3.1 percent for those who gained. Furthermore, those who chose the balance fee lost more than those who chose the load fee. Among the individuals assigned to the balance fee, the average size of the change in the final pension balance for those who lose is -7.0 percent and for those who gain, 0.9 percent. Among the individuals who opted for the load fee, the average size of the change in the final pension balance is -1.3 percent for those who lose, and 3.6 percent for those who gain. We also find important differences in losses and gains across age group as well as income and retirement wealth distribution. Younger and poorer individuals show higher losses.

After conducting several other robustness checks, we find that our main result stands: a significant number of people are worse off due to the reform. 
The remainder of the paper is organized as follows: Section 2 gives an overview of the institutional background and the pension management fees reform. Section 3 describes the data and variables. Section 4 presents the methodology. Section 5 provides the main results and Section 6 presents some robustness checks and further results. Section 7 concludes.

\section{Background}

\subsection{The Private Pension System}

The government introduced the IRA system in 1992 as the Private Pension System (SPP due to its Spanish name). It launched the system following the pioneering experience of Chile in 1981, although it did not dismantle the National Pension System (known as SNP) as Chile and other Latin American countries did during their pension reforms. Thus, workers were free to enroll in either the SPP or SNP.

Participation in either the SPP or the SNP is mandatory only for individuals who are formally registered on a payroll; that is, employees in the formal sector. About 37 and 27 percent of the total labor force were in the SPP and SNP, respectively, in 2015. However, many individuals do not contribute regularly or do not contribute at all because of frequent transition between the formal and informal sectors. The shares of individuals in the labor force who contributed regularly to the SPP and SNP were about 17 and 10 percent, respectively, in 2015.

The AFP (Administradora Privada de Fondos de Pensiones in Spanish) manages the individual accounts of the SPP. There are currently four AFPs in the system: Prima, Integra, Profuturo and Habitat. ${ }^{3}$ Workers are the sole contributors to the AFP at a rate of 10 percent of the their monthly gross wage. ${ }^{4}$ Two additional charges are also paid by the worker. The first one is a premium paid to insurance firms to cover disability and mortality risks, and the second one is a management fee paid to the AFP. The employer deducts both the insurance and the management fee from the monthly gross wage, but in the case of the insurance there is a cap applied to the wage.

Peru has been part of a new wave of second-generation pension reforms (Kritzer et al. (2011)) focused on closing coverage gaps and reducing administrative costs of IRA systems. In this context, the government passed an important reform of the SPP in July 2012 (Law $\mathrm{N}^{\circ}$ 29903) that went into effect the following year. The main goal of the reform was to increase efficiency (through reductions in private costs) and to improve pension coverage and contributions. One important aspect of the reform was the charging of administrative fees. A new fee based on each individual's pension balance was established.

\footnotetext{
${ }^{3}$ Other AFPs existed (Unión Vida, Horizonte) but opted out of the market over time.

${ }^{4}$ The contribution rate has been different than 10 percent. In 1993-1995, it was 11 percent, which included a solidarity charge and, from 1995-2005, the Government reduced the rate to 8 percent. Since 2005, the Government has maintained the contribution rate at 10 percent.
} 
The 2012 reform also introduced two auction schemes with the primary objective of reducing administrative fees. One concerns the choice of which AFP will enroll all the new workers for two years, and the other concerns the choice of which insurance firm that will provide the disability and mortality coverage. Both schemes are a type of reverse auction (Kurach and Kusmierczyk (2017)) where the firms bid to provide pension fund management or insurance services to the clients. Because firms with the lowest prices would win the bid in this type of auction, the government expected a reduction in the fees paid by the individuals. The reform also strove to enhance efficiency by allowing the AFP to centralize operations (i.e. contributions collection, provision of benefits, etc.) and to use new financial instruments to increase portfolio diversification. While it was eventually removed or never implemented, the reform also established mandatory enrollment for self-employed people aged 40 and younger and for individuals working in small firms whose contributions would then be subsidized by the government.

\subsection{Management fee reform}

Figure 1 illustrates the evolution of the load factor fee from 2000 to 2018 . The figure shows a reduction from 2.39 percent in February 2000 to 1.58 percent in February 2018, although most of this variation took place between 2005 and 2013. This reduction seems related to the entry of new pension fund managers. Indeed, in August 2005 AFP Prima started operations and charged a fee much lower than the market average (1.50 versus 2.11 percent, on average) that in turn triggered price reductions in January 2006 by AFP Profuturo and AFP Unión Vida. However, these reductions did not last long because in December 2008, AFP Prima increased its fee to 1.75 percent, with AFP Profuturo nine months later. In July 2013, AFP Habitat entered the market with a fee of 1.47 percent, the lowest in the system. These fees have not varied since. ${ }^{5}$

The government passed a broader reform on July 19, 2012, but the details were published on November 8, 2012. Individuals could choose their preferred fee between January 2, 2013 and May 31, 2013, before the new scheme went into effect on June 1, 2013. More precisely, the default option was the balance fee, so those individuals preferring to choose the load factor fee had a window of five months to follow certain procedures. The only option for new individuals enrolling in an AFP after February 1, 2013 was the balance fee.

To choose the load factor fee, individuals had to communicate their decision to the AFP and sign some authorization forms. There was a period of approval of around four weeks during which individuals were required to record the confirmation of their decision by phone. Furthermore, the reform established a cooling-off period of six months after June 1, 2013 to allow individuals to reverse their decision of staying with the load factor fee. By December 2013, 35 percent (1.92 million) of individuals were staying with the previous load factor fee, while 65 percent had chosen the new balance fee.

\footnotetext{
${ }^{5}$ See Table A.2 for details on the fee levels of AFP up to December 2016. These values did not change until February 2018. Regarding the insurance premium, the cost increased from 1.23 percent in December 2013 to 1.36 percent in December 2017.
} 
Figure 1: Evolution of Fees in the Load Factor Fee Scheme

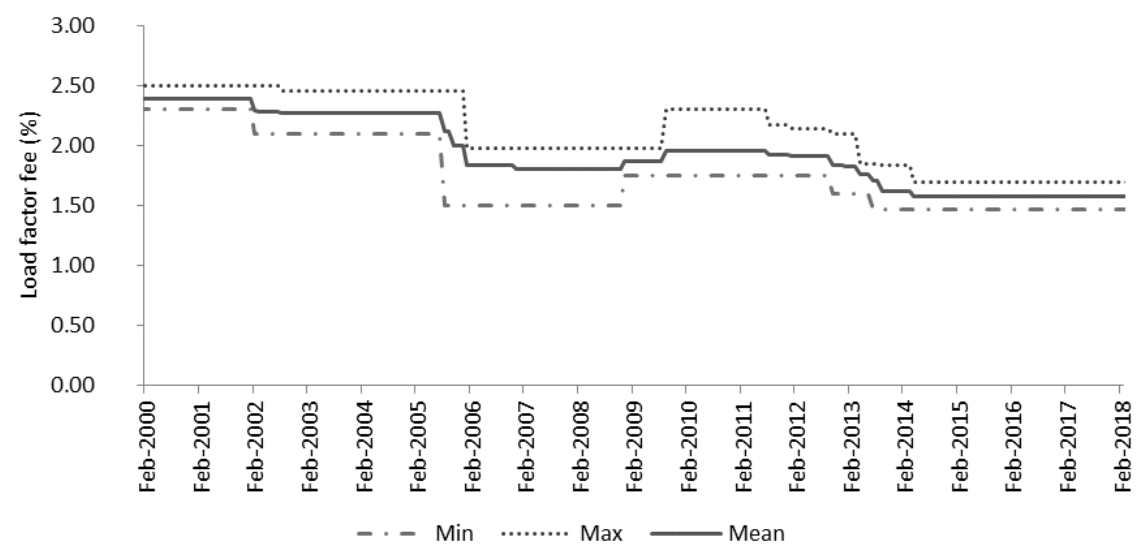

Notes: The figure shows monthly values (Feb 2000 to Feb 2018) of load factor fees extracted from SBS's official statistics. The mean corresponds to the simple average of fees.

It is worth noting that the balance fee scheme includes a temporary load factor fee that (by regulation) will gradually decrease down to zero by 2023 and a balance fee that will remain indefinitely.

Figure 2 shows the evolution of the two types of fees that are part of the balance fee scheme. In February 2013, the average load factor fee was 1.51 percent, whereas in February 2018 it was 0.63 percent; this is a significant reduction in a five-year period. There is some variance among AFPs. For example, AFP Prima and AFP Habitat offered the lowest prices, 0.18 and 0.38 percent, respectively, whereas AFP Profuturo was the most expensive at 1.07 percent. While the reform has reduced the load factor fee over the last five years, the balance fee has not changed since June 2013 when its average value was 1.23 percent. One reason for this is that the reform mandates an explicit minimal reduction in the load factor fee (until it reaches zero in 2023) while it says nothing about the balance fee. ${ }^{6}$ The main assumption of the government seems to be that the reverse auctions would lead - through more competition - to a reduction in the balance fees. However, this has not occurred. ${ }^{7}$

\footnotetext{
${ }^{6}$ According to specific rules generated by the reform, the temporary load factor fee included in the balance fee scheme had to be reduced by 86.5 percent for the period from February 2013 to January 2015, 65.8 percent from February 2015 to January 2017, 50.0 percent from February 2017 to January 2019, 31.5 percent from February 2019 to January 2021 and 13.5 percent from February 2021 to January 2023, until the load factor fee reaches zero in February 2023.

${ }^{7}$ Between 2012 and 2018, there were three auctions. Habitat won the first one in 2013 and held the monopoly on the enrollment of new workers until May of 2015. The prices in the balance fee scheme were $0.47 \%$ for the load factor fee and $1.25 \%$ for the balance fee. In the second auction, Habitat won again with prices of $0.38 \%$ and $1.25 \%$, respectively. In the third process, Prima won the bid (valid until May 2019) with prices of $0.18 \%$ and $1.25 \%$, respectively. Pension funds seem to compete by reducing the transitory load factor fee of the balance fee scheme but not the balance fee.
} 
Figure 2: Evolution of Fees in the Balance Fee Scheme

(a) Temporary Load Factor Fee

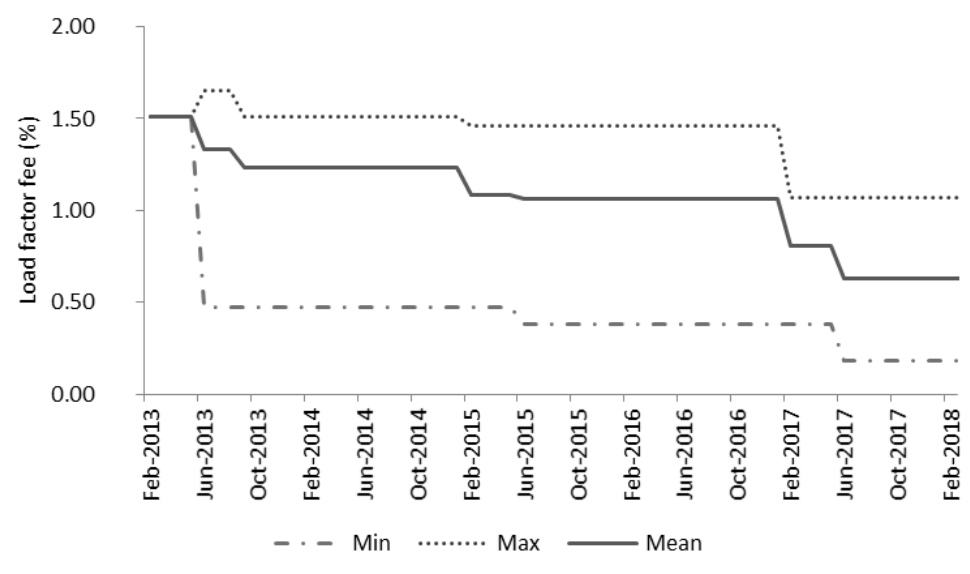

(b) Balance Fee

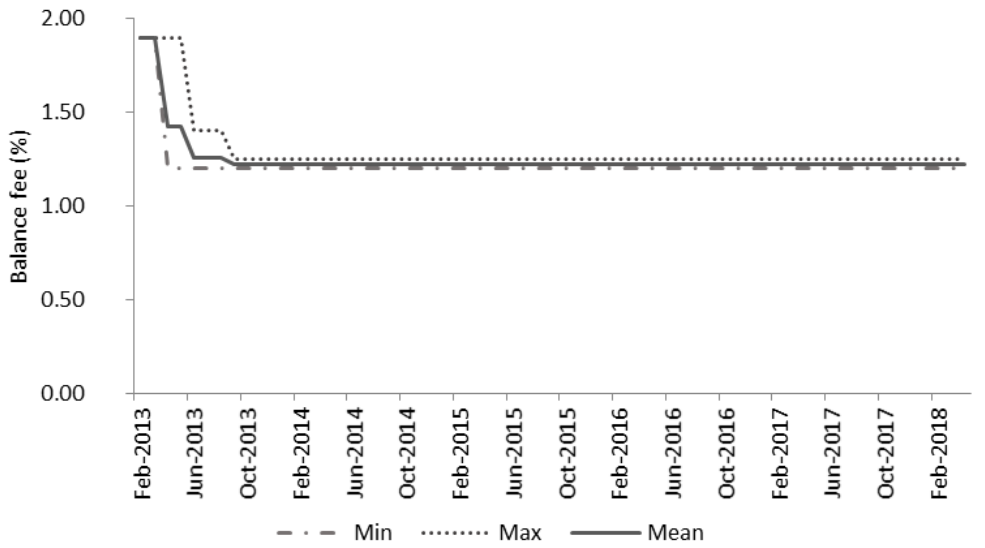

Notes: The figures show the monthly values (from February 2013 to February 2018) of the temporary load factor and balance fees of the balance fee scheme extracted from SBS's official statistics. The mean corresponds to the simple average of the fees. By regulation, the temporary load factor fee will be zero for all individuals from February 2023.

It is worth noting that the original reform proposed by the SBS intended to fully replace the load fee with the balance fee for all individuals, but Parliament intervened and allowed the individuals to choose the load fee. Given that the adopted fees are not reversible, the policy has generated a trap: potential reductions in the balance fees (relative to the load fee scheme) cannot be taken advantage of by the individuals who actively chose the load fee scheme.

\section{Data}

We use a sample of 2 percent of the total non-retired population from SBS's individual administrative registers as of December 2016. The sample is random, stratified and representative of the following strata: 5-year age group, sex and enrollment year. It is the only available data set that includes information about each individual's type of management fee, pension balance, 
income and some socio-economic variables.

The initial sample size is composed of 100,024 observations, which correspond to individuals aged 21 to 64 who enrolled in the SPP before 2013. Individuals who enrolled in 2013 or later have not been able to choose a preferred fee scheme and hence are not part of our sample framing. After applying some selections related to the focus of our analysis, we obtain a sample of 64,588 observations. To arrive at this number we drop 9,129 individuals with pension balance of zero and 63 whose balances are missing. Many of these individuals have unregistered income or their enrollment in the SPP occurred long time ago. ${ }^{8}$ If an individual became affiliated with the SPP a long time ago and also have an empty balance, she might be an infrequent contributor or not contribute at all. Given our interest in studying the prospective effects of the reform on individuals for whom the reform is relevant, we restrict our sample to those who are current contributors. We define these individuals as those whose last registered contribution occurred at least in 2013 (after applying this definition, 14,546 individuals are dropped). Note that this is a somewhat flexible criterion because in practice, we are considering individuals who made at least one contribution in four years, between 2013 and 2016. ${ }^{9}$ Furthermore, we drop 11,656 individuals who have not registered incomes or last contribution date. Finally, 42 individuals caught in the transition procedure for retirement are also dropped.

Given these selections, our final sample contains individuals with relatively higher incomes, pension savings and probability of contributing. We are interested in this type of individuals because the reform will be relevant for them, and we acknowledge that our analysis cannot be extrapolated to the total population of the SPP (see Table A.3 in the appendix for more details).

The data contain demographic information on age, gender, employment condition and income at the individual level. The data also include information on the pension account, such as the enrollment date, AFP, last contribution date, pension balance, balance affected and unaffected by the reform, type of chosen or allocated fee, type of pension fund, contribution density, and information about recognition bonds. This bond is an amount of money, based on past contributions, guaranteed by the government to those that were previously affiliated with the national pension system.

There are four main types of pension funds. Fund type 1, which includes investments with relatively low returns and volatility, is mandatory for individuals aged 60-65 unless the individual chooses fund type 0 or 2 . Fund type 2 includes investments with moderate growth and volatility and combines both fixed-income instruments and equities. Fund type 3 is generally composed of investments with higher returns and volatility such as equities. Fund type 0 is designed to maintain capital, offers low returns and volatility and is intended for individuals in the process of retirement after age $65 .^{10}$ When an individual enrolls for the first time into

\footnotetext{
${ }^{8}$ Of all these cases, 81 percent have enrolled in 2006 or earlier.

977.2 percent of individuals in the final sample made their last pension contribution in 2016, 9.3 percent in 2015, 7.3 percent in 2014, and 6.2 percent in 2013.

${ }^{10}$ Fund type 1 invests up to 100 percent in short-term fixed-income instruments and up to 10 percent in equities; fund type 2 invests up to 75 percent in short-term fixed-income instruments and up to 45 percent in equities; and
} 
an AFP, the default pension fund is type 2; choosing another type of pension fund requires a special administrative procedure. We use these pension fund defaults to compute a measure of how active individuals are regarding their portfolio management. The variable Active portfolio management takes the value of one if an individual under 60 has a pension fund type 1 or 3 or if an individual older than 60 has a pension fund other than type 1, and takes value zero otherwise. This variable indicates that the individual has taken action to move away from the default pension fund portfolio. We argue that this variable captures awareness about risk diversification and may therefore be a proxy for financial literacy. We expect that more sophisticated individual investors will be more likely to deviate from the defaults.

We use two additional and similar samples of SBS's data from 2006 and 2013 to compute the growth rates of labor income based on gender, income quintile and birth cohort (see Table A.4 in the appendix for more details).

Table 1 shows the descriptive statistics of the variables in our final sample as of December 2016. The information is shown for all individuals and by type of fee scheme. We construct quintiles of income, pension balance and contribution density. The quintiles are specific by birth cohorts as of 2016 and grouped by five-year increments (21-25, 26-30...61-64) in order to reduce life-cycle effects. The type of occupation, employee or self-employed, corresponds to that recorded in the last contribution. The date of the last contribution indicates the last time the individual was registered in an occupation where she contributed to a pension fund. As pension contribution is compulsory only for formal sector employees, we cannot clearly observe whether or not the individual was unemployed.

In this sample, 53 percent of individuals $(34,237)$ chose the load factor fee, while 47 percent $(30,351)$ were assigned to the balance fee. This is interesting for our analysis because choosing the load factor fee is an active decision; individuals had to inform the AFP and follow a specific procedure. Despite this transaction cost, a significant portion of our population of interest seems to have opted for it.

On average, individuals assigned to the balance fee are younger than those who chose the load factor fee (38 versus 41 years old), more predominantly male (69 percent versus 61 percent), have spent less time in the SPP (8.3 versus 10.4 years), and have lower pension balances (S/.20,244 versus S/.50,316) and incomes (S/.1,872 versus S/.3,194, on average). The frequency or density of contributions also differs significantly. Individuals assigned to the balance fee contribute during, on average, 47 percent of the time they are enrolled, while individuals who chose the load factor fee contribute 79 percent of the time.

A sort of revealed preference for risk can be inferred from the distribution of individuals among the different fund types. The large majority of individuals, regardless of the fee scheme, invest their funds in the fund type 2, the default and moderate-risk portfolio. However, within those who opted for the load factor fee, the proportion of individuals who choose a riskier 
Table 1: Mean Differences among Individuals by Actual Fee

\begin{tabular}{|c|c|c|c|c|c|c|c|c|c|c|}
\hline \multirow[t]{2}{*}{ Variable } & \multirow[t]{2}{*}{ Dummy } & \multicolumn{2}{|c|}{$\begin{array}{c}\text { Overall } \\
(\mathrm{N}=64,588)\end{array}$} & \multicolumn{2}{|c|}{$\begin{array}{l}\text { Balance fee } \\
\qquad(\mathrm{N}=30,351)\end{array}$} & \multicolumn{2}{|c|}{$\begin{array}{l}\text { Load factor } \\
\text { fee } \\
\qquad(\mathrm{N}=34,237)\end{array}$} & \multicolumn{2}{|c|}{ Mean diff } & \multirow[b]{2}{*}{$\mathrm{p}$-value } \\
\hline & & Mean & S.E. & Mean & S.E. & Mean & S.E & Mean & S.E. & \\
\hline Male & $\mathrm{D}$ & 0.651 & & 0.694 & & 0.613 & & 0.081 & 0.004 & 0.000 \\
\hline Age & & 39.663 & 9.810 & 38.401 & 9.874 & 40.782 & 9.615 & -2.381 & 0.077 & 0.000 \\
\hline Balance not charged with fee (S/. '000) & & 33.907 & 92.148 & 15.397 & 50.395 & 50.316 & 114.868 & -34.919 & 0.685 & 0.000 \\
\hline Balance charged with fee (S/. '000) & & 2.278 & 8.043 & 4.847 & 11.190 & 0.000 & 0.000 & & & \\
\hline Total saving balance (S/. '000) & & 36.185 & 93.801 & 20.244 & 57.973 & 50.316 & 114.868 & -30.072 & 0.704 & 0.000 \\
\hline 1st quintile & $\mathrm{D}$ & 0.200 & & 0.357 & & 0.061 & & 0.296 & 0.003 & 0.000 \\
\hline 2nd quintile & $\mathrm{D}$ & 0.200 & & 0.240 & & 0.165 & & 0.075 & 0.003 & 0.000 \\
\hline 3th quintile & $\mathrm{D}$ & 0.200 & & 0.173 & & 0.224 & & -0.051 & 0.003 & 0.000 \\
\hline 4th quintile & $\mathrm{D}$ & 0.200 & & 0.134 & & 0.259 & & -0.125 & 0.003 & 0.000 \\
\hline 5th quintile & $\mathrm{D}$ & 0.200 & & 0.097 & & 0.291 & & -0.195 & 0.003 & 0.000 \\
\hline Monthly labor income (S/.) & & $2,572.8$ & $6,622.2$ & $1,871.8$ & $5,818.8$ & $3,194.3$ & $7,203.8$ & $-1,322.4$ & 51.296 & 0.000 \\
\hline 1st quintile & $\mathrm{D}$ & 0.206 & & 0.287 & & 0.135 & & 0.152 & 0.003 & 0.000 \\
\hline 2nd quintile & $\mathrm{D}$ & 0.195 & & 0.223 & & 0.170 & & 0.053 & 0.003 & 0.000 \\
\hline 3th quintile & $\mathrm{D}$ & 0.199 & & 0.198 & & 0.200 & & -0.003 & 0.003 & 0.366 \\
\hline 4th quintile & $\mathrm{D}$ & 0.201 & & 0.169 & & 0.229 & & -0.059 & 0.003 & 0.000 \\
\hline 5th quintile & $\mathrm{D}$ & 0.199 & & 0.123 & & 0.266 & & -0.143 & 0.003 & 0.000 \\
\hline Contribution density & & 0.638 & 0.326 & 0.468 & 0.322 & 0.788 & 0.246 & -0.320 & 0.002 & 0.000 \\
\hline 1st quintile & $\mathrm{D}$ & 0.200 & & 0.370 & & 0.050 & & 0.320 & 0.003 & 0.000 \\
\hline 2nd quintile & $\mathrm{D}$ & 0.200 & & 0.258 & & 0.148 & & 0.110 & 0.003 & 0.000 \\
\hline 3th quintile & $\mathrm{D}$ & 0.200 & & 0.166 & & 0.230 & & -0.064 & 0.003 & 0.000 \\
\hline 4th quintile & $\mathrm{D}$ & 0.200 & & 0.113 & & 0.277 & & -0.164 & 0.003 & 0.000 \\
\hline 5th quintile & $\mathrm{D}$ & 0.200 & & 0.093 & & 0.295 & & -0.202 & 0.003 & 0.000 \\
\hline Self-employed & $\mathrm{D}$ & 0.028 & & 0.031 & & 0.025 & & 0.006 & 0.001 & 0.000 \\
\hline Years enrolled in SPP & & 9.389 & 6.149 & 8.265 & 6.019 & 10.386 & 6.091 & -2.121 & 0.048 & 0.000 \\
\hline AFP Integra & $\mathrm{D}$ & 0.398 & & 0.387 & & 0.408 & & -0.021 & 0.004 & 0.000 \\
\hline AFP Profuturo & $\mathrm{D}$ & 0.329 & & 0.364 & & 0.298 & & 0.066 & 0.004 & 0.000 \\
\hline AFP Prima & $\mathrm{D}$ & 0.269 & & 0.246 & & 0.289 & & -0.044 & 0.003 & 0.000 \\
\hline AFP Habitat & $\mathrm{D}$ & 0.004 & & 0.003 & & 0.005 & & -0.001 & 0.000 & 0.007 \\
\hline Fund type 1 (secure) & $\mathrm{D}$ & 0.036 & & 0.030 & & 0.041 & & -0.012 & 0.001 & 0.000 \\
\hline Fund type 2 (moderate) & $\mathrm{D}$ & 0.892 & & 0.923 & & 0.865 & & 0.059 & 0.002 & 0.000 \\
\hline Fund type 3 (risky) & $\mathrm{D}$ & 0.072 & & 0.047 & & 0.094 & & -0.047 & 0.002 & 0.000 \\
\hline Active portfolio management & $\mathrm{D}$ & 0.079 & & 0.051 & & 0.105 & & -0.053 & 0.002 & 0.000 \\
\hline Have recognition bond & $\mathrm{D}$ & 0.040 & & 0.021 & & 0.056 & & -0.035 & 0.001 & 0.000 \\
\hline
\end{tabular}

Note: The table uses the analyzed sample of SBS administrative registers as of December 2016. The mean differences are computed using twosample t-tests by groups (balance and load factor fee schemes) with unequal variances. The means with finite variance of variables of income, contribution density and pension balance have normal distribution. The test on the equality of proportions is used for dummy variables. 
portfolio (composed of up to 80 percent equities) is double the proportion observed within those who were assigned to the balance fee (9.4 versus 4.7 percent), might mean that they are a more financially sophisticated group. Furthermore, there are more individuals actively involved in portfolio management (our proxy for financial literacy) within the group choosing the load factor fee than in the group choosing the balance fee (10.5 versus 5.1 percent).

In summary, the individuals who decide to keep the load factor fee are slightly older, have spent more time in the SPP, are more likely to be women, earn higher incomes, have more pension savings, contribute more often, have slightly more tolerance of risk and are more active in portfolio management than the group of individuals who choose the balance fee. Differences by gender are reported in Table A.5 in the appendix.

\section{Assessing the choice of fee}

\subsection{Charge ratios}

We seek to evaluate the potential effect of the choice of fee scheme on the level of pension wealth; that is, on the final balance accrued for retirement. An illustrative and easily implementable measure for this purpose is the so-called "charge ratio" (Whitehouse (2001), Tapia and Yermo (2008), Murthi et al. (1999), Aguila et al. (2014)). The charge ratio indicates the proportion of fees in the accumulated fund:

$$
\begin{gathered}
\lambda^{l}=\left[1-\frac{S^{l, f e e}}{S^{l, \text { nofee }}}\right] \\
\lambda^{m}=\left[1-\frac{S^{m, f e e}}{S^{\text {m,nofee }}}\right]
\end{gathered}
$$

$\lambda^{l}$ and $\lambda^{m}$ are the charge ratios for the load and balance fees, respectively, computed at 65 , the age of retirement. The value of $S^{l, f e e}$ is the balance an individual would obtain with her pension contributions under the load factor fee, while $S^{l, n o f e e}$ is the balance she would obtain if both contribution and fee were accumulated in the pension fund account. Similar definitions apply for the funds accrued under the balance fee, defined as $S^{m, f e e}$ and $S^{m, n o f e e}$. The most convenient fee scheme for an individual is the one with a lower charge ratio. Thus, if $\lambda^{l}<\lambda^{m}$, then the load factor fee would be the best option for the individual. The rationale behind the charge ratio is that it can reveal which scheme allows an individual to obtain a higher final fund relative to the invested amount.

Our strategy consists of, for each individual, comparing the charge ratios of both fees - that of the fee actually chosen and that of the other fee if it had instead been selected. So, each individual case serves as its own control. 


\subsection{Simulation}

The computation of charge ratios requires the estimation of the individual's future balance under each fee scheme: $S^{l, f e e}, S^{l, n o f e e}, S^{m, f e e}$, and $S^{m, n o f e e}$. We denote $d_{j t}$ as a percentage deducted from the individual's income $\left(w_{t}\right)$ including the pension contribution $\left(c_{t}\right)$ to the savings account and the management fee, $a_{j t}$, with $j=1,2,3$ indicating the type of fee. Under the load factor fee, the unique charge is $a_{1 t}$, so that the income deduction is $d_{1 t}=c_{t}+a_{1 t}$. The balance fee scheme includes both a load factor fee, $a_{2 t}$, that will gradually decrease down to zero in 2023 , and a balance fee, $a_{3 t}$, that is levied as a proportion of the balance and will remain indefinitely. Thus, under this scheme, the deduction is $d_{2 t}=c_{t}+a_{2 t}$ up to 2023 and $d_{2 t}=c_{t}$ afterwards. Individuals make pension contributions with probability $p_{t}$, and the savings balances earn returns $r_{t}$. The individuals also pay an insurance premium to private firms, but we do not include it in the simulation. The accumulation of the savings balance follows a monthly $(t)$ discrete process:

$$
\begin{gathered}
S_{t+1}^{l, f e e}=S_{t}\left(1+r_{t}\right)+p_{t+1}\left(d_{1 t+1}-a_{1 t+1}\right) w_{t+1} \\
S_{t+1}^{m, f e e}=S_{0}\left(1+r_{t}\right)+S_{t}^{a}\left(1+r_{t}\right)\left(1-a_{3 t+1}\right)+p_{t+1}\left(d_{2 t+1}-a_{2 t+1}\right) w_{t+1}
\end{gathered}
$$

Equations 3 and 4 describe the accumulation processes for individuals who choose the load factor fee and those who choose the balance fee, respectively. In equation 4 , the balance fee $\left(a_{3 t}\right)$ applies only to the new savings accumulated after the reform $\left(S_{t}^{a}\right)$ and not to the previously accrued balance $\left(S_{0}\right)$.

To compute the charge ratios for each fee scheme, we also use the counterfactual pension balance assuming pension contributions and fees are invested in the individual balance. For this purpose, we define the following accumulation processes:

$$
\begin{gathered}
S_{t+1}^{l, n o f e e}=S_{t}\left(1+r_{t}\right)+p_{t+1} d_{1 t+1} w_{t+1} \\
S_{t+1}^{m, n o f e e}=S_{0}\left(1+r_{t}\right)+S_{t}^{a}\left(1+r_{t}\right)+p_{t+1} d_{2 t+1} w_{t+1}
\end{gathered}
$$

The future balances (equations 3, 4, 5 and 6), and therefore the charge ratios, critically depend on the combination of values set for the fees. The following example illustrates this point. Assume individuals live for two periods; in the first they contribute and in the second they retire. They do not have a previously accrued balance and their probability of contributing is equal to one. Under the balance fee scheme, the final balances are $S^{m, f e e}=c w(1+r)\left(1-a_{3}\right)$ and $S^{m, n o f e e}=\left(c+a_{2}\right) w(1+r)$. On the other hand, under the load factor fee scheme, the final balances are $S^{l, f e e}=c w(1+r)$ and $S^{l, n o f e e}=\left(c+a_{1}\right) w(1+r)$. Therefore, the computed charge ratios are $\lambda^{l}=1-\frac{c}{\left(c+a_{1}\right)}$ and $\lambda^{m}=1-\frac{c\left(1-a_{3}\right)}{\left(c+a_{2}\right)}$. We cannot easily distinguish which scheme offers a lower charge ratio - the best scheme for the individual - as the values of the charge ratios 
crucially depend on the values of the contribution rate and fees.

Interestingly, the difference between charge ratios $\left(\Delta_{m l}=100 \times\left(\lambda^{m}-\lambda^{l}\right)\right)$ can indicate the degree of loss or gain in terms of the percentage change in the final savings balance due to the choice of a fee scheme. The gains of an individual choosing the load factor fee are equal to $\Delta_{m l}$ if $\lambda^{l}<\lambda^{m}$ and her losses are equal to $\Delta_{m l}$ if $\lambda^{l}>\lambda^{m}$. In the case of an individual choosing the balance fee, her gains are equal to $-\Delta_{m l}$ if $\lambda^{l}>\lambda^{m}$, and her losses are equal to $-\Delta_{m l}$ if $\lambda^{l}<\lambda^{m}$.

The four balance types are simulated for each individual from January 2017 until each individual reaches 65 . In this exercise, we cannot use the fees already paid between the dates of policy implementation (June 2013) and our sample (December 2016), but the effect on the charge ratios should be rather small due to the short period.

The fees are assumed to be equal to their current levels (as of December 2016) for the simulation period, except for the temporary load factor fees of the balance fee scheme, which have to steadily decline to zero on February 2023. ${ }^{11}$ Labor income evolves at growth rates specific to gender, income quintile and birth cohort - that are estimated using SPP's individual data from years 2006 and 2013.

The probability of making pension contributions $p_{t}$ is proxied by the observed contribution density, which is the number of months with contributions over the total number of months enrolled in the SPP. The available densities of individuals' contributions in the administrative data begin in May 2006, as the records before this date are less reliable.

The investment return rate is a crucial determinant of retirement wealth. By regulation, pension fund managers use the so called "share value", which is the unit of measure of the fund's value. Share values are calculated and published daily by the SBS. The pension balance of an individual in period $t$ is the number of shares in the pension fund that the individual holds at $t$ multiplied by the share value of period $t$. Similarly to Chávez-Bedoya (2017), we assume that the share values follow the stochastic process in a Geometric Brownian Motion (GBM), that has both a deterministic and random Wiener component:

$$
d V(t)=\mu V(t) d t+\sigma V(t) d W(t)
$$

$V(t)$ indicates the share value in period $t$ (with $V(0)=V_{0}$ ); $W(t)$ is a Wiener process or Brownian motion; $\mu$ denotes the average return and $\sigma$ denotes the volatility. The first component of equation 7 is used to model deterministic trends, while the second one is used to model a set of unpredictable events occurring during this motion. To model this process, we use data from AFP Integra's pension fund from January 2001 to December 2017. We chose this pension fund because it contains an important share of the market and has been part of the SPP since

\footnotetext{
${ }^{11}$ The values are as follows: i) load factor fee: 1.55 percent for Integra, 1.60 for Prima, 1.69 for Profuturo and 1.47 for Habitat; ii) temporary load factor fee in the balance fee scheme: 1.23 percent for Integra, 1.19 for Prima, 1.46 for Profuturo and 0.38 for Habitat; iii) balance fee in the balance fee scheme: 1.20 percent for Integra, 1.25 for Prima, 1.20 for Profuturo and 1.25 for Habitat. See Table A.2 in the appendix for more details. In the section on sensitivity checks, we consider alternative values for fees.
} 
the beginning of the system without any merge or acquisition. For the deterministic component, we assume an average real annual rate of return of 5 percent. This assumption follows SBS (2013) and is based on the fact that as an economy registers sustainable growth and its stock market develops, the country's risk and pension fund returns should reduce. The evidence from OECD countries shows that real annualized rates of pension funds were lower than 5 percent between 2002 and 2011. Furthermore, the annualized rate of returns of the Chilean private pension system (which has been in place for more than 35 years) decreased from 14 percent in the first 10 years of operation to 5 percent over the 30 years of operations. Volatility is set at $\sigma=1.27$ percent, which is the figure arising from the returns (excluding 2005-2011 due to abnormal returns). We conduct 1,000 GBM simulations in order to obtain different paths for the share values and, therefore, different paths for the rates of returns. We take the average of all the simulations for the share values.

The first results for the computed values of charge ratios show large heterogeneity. For example, the simulations reflect that, on average, the load factor fee is better for individuals younger than 40 (at the moment of the policy implementation), while the balance fee is generally better for older individuals (see Table A.6 in the appendix). Clearly, many individuals inadvertently chose the less advantageous fee scheme and for many others, the new default scheme was not the best option. The next section will more carefully analyze individual choice and its consequences.

\section{Results}

\subsection{Who gains and who loses with the policy?}

Table 2 summarizes our main results. The columns indicate whether each individual falls into the balance fee (default) or deliberately chooses the load fee. Based on the comparison of charge ratios arising from our simulations, the rows specify which fee scheme is better for the individual.

We find that the policy reform is beneficial to only 36.9 percent of the individuals in our sample, while it is adverse to 63.1 percent. On the one hand, 3,604 individuals benefit from the balance fee and 20,239 benefit from the load factor fee. So, only a total of 23,843 out of 64,588 individuals (36.9 percent) made the right choice and chose the fee with the lower charge ratio at the time the policy gave them the chance to do so. On the other hand, a total of 40,745 individuals (63.1 percent) actively chose the worse fee or were assigned to the default despite its disadvantages. For individuals assigned to the balance fee, 88 percent $(=26,747 / 30,351)$ are currently losing money in comparison to the balance they would have had under the load factor fee. Similarly, among the individuals who chose the load factor fee, 41 percent $(=13,998 / 34,237)$ made the wrong decision. They would be better off under the default option. We can interpret the causes of this overall negative result as both unintended policy effects and an lack of soundness 
in individual financial decisions. ${ }^{12}$

Table 2: Winners and Losers with the Balance and Load Factor Fees

\begin{tabular}{lccc}
\hline & \multicolumn{2}{c}{ Actual fee } & \\
\cline { 2 - 3 } & $\begin{array}{c}\text { Balance fee } \\
\text { (default option) }\end{array}$ & $\begin{array}{c}\text { Load factor fee } \\
\text { (active choice) }\end{array}$ & Total \\
\hline Balance fee is better & 3,604 & 13,998 & 17,602 \\
Load factor fee is better & 26,747 & 20,239 & 46,986 \\
Total & 30,351 & 34,237 & 64,588 \\
\hline
\end{tabular}

Note: One fee scheme is better than the other one if it has a lower charge ratio. The columns under Actual fee indicate the current fee of the individual.

As mentioned before, the original policy reform promoted by the government was amended by the Parliament, which compromised the consistency of the policy. Originally, the government intended to fully replace the load factor fee with a balance fee for all individuals and expected a declining trend of fees driven by competition among pension funds. However, the intervention of the Parliament, which allowed individuals to remain in the load fee scheme, reduced the mass of contributors who could pay the balance fee and therefore might have limited the reduction of fees due to competition. Other important reasons for our results could be passive choice and complexity (Beshears et al. (2008)). Recall that many individuals in our sample did not make an active choice and accepted the default scheme (passive choice). This acceptance might reflect a conscious decision, but is more likely to reflect procrastination or inertia, because the marginal cost of procastinating was small (i.e. no paperwork or monetary cost was required to subscribe to the new balance fee, but a great deal of paperwork was required to remain in the load factor fee). Therefore, is not surprising that many individuals' preferences revealed in our sample are inconsistent. On the other hand, the complexity of the reform (i.e. a temporary load factor and balance fee embedded in the balance fee scheme) might also have increased the proportion of individuals who simply accepted the default. This complexity also might have added noise or biased choices because individuals may not have thoroughly understood the options and deadlines, may have decided to avoid thinking about complicated alternatives or may have even chosen a complicated alternative without estimating the future impact. Finally, low financial literacy could also drive our results; one can imagine that the effects of passive choice and complexity might be even stronger for individuals who lack financial knowledge. We are not able, unfortunately, to analyze inertia or complexity, but we are able to explore financial literacy in our data.

To this end, we run a probit model to determine the likelihood of an individual choosing the load fee. Table 3 displays the results. The regressions include regional (individual's region

\footnotetext{
${ }^{12}$ Table A.7 in the appendix shows important differences in the percentage of individuals making a right or wrong choice across AFP. With 32.3 percent, Profuturo has the lowest share of persons making the right choice, while this percentage is 37.1, 42.1 and 42.5 percent in Integra, Prima and Habitat, respectively.
} 
of residence) fixed effects in order to control for possible unobservables at the region level. The table reports the marginal effects on the probability that the individual will choose the load factor fee. The dependent variable equals one if the individual chooses the load factor fee and zero otherwise. The only difference between the two model specifications displayed in Table 3 is that the first uses the pension fund type of the individual, while the second includes a variable measuring whether the individual actively manages her pension fund portfolio, which may capture financial literacy.

Table 3: Probability of Choosing the Load Factor Fee

\begin{tabular}{|c|c|c|c|c|}
\hline & \multicolumn{2}{|c|}{ Model 1} & \multicolumn{2}{|c|}{ Model 2} \\
\hline & Coef. & S.E. & Coef. & S.E. \\
\hline Male & $-0.1074 * * *$ & $(0.0046)$ & $-0.1075^{* * *}$ & $(0.0046)$ \\
\hline Age & $0.0026 * * *$ & $(0.0004)$ & $0.0021 * * *$ & $(0.0004)$ \\
\hline Contribution density & $0.6206 * * *$ & $(0.0110)$ & $0.6237 * * *$ & $(0.0110)$ \\
\hline Pension balance - 2 nd quintile & $0.1520 * * *$ & $(0.0076)$ & $0.1503 * * *$ & $(0.0076)$ \\
\hline Pension balance - 3th quintile & $0.1914 * * *$ & $(0.0088)$ & $0.1885^{* * *}$ & $(0.0088)$ \\
\hline Pension balance - 4th quintile & $0.2096 * * *$ & $(0.0099)$ & $0.2059 * * *$ & $(0.0099)$ \\
\hline Pension balance - 5th quintile & $0.2382 * * *$ & $(0.0114)$ & $0.2334 * * *$ & $(0.0114)$ \\
\hline Income - 2nd quintile & 0.0100 & $(0.0070)$ & 0.0101 & $(0.0070)$ \\
\hline Income - 3th quintile & $0.0362 * * *$ & $(0.0070)$ & $0.0366 * * *$ & $(0.0070)$ \\
\hline Income - 4th quintile & $0.0496 * * *$ & $(0.0073)$ & $0.0500 * * *$ & $(0.0073)$ \\
\hline Income - 5th quintile & $0.0637 * * *$ & $(0.0085)$ & $0.0643 * * *$ & $(0.0085)$ \\
\hline Self-employed & $0.0557 * * *$ & $(0.0136)$ & $0.0547 * * *$ & $(0.0136)$ \\
\hline Years enrolled in SPP & $0.0017 * * *$ & $(0.0006)$ & $0.0021 * * *$ & $(0.0006)$ \\
\hline AFP Profuturo & $-0.0134 * * *$ & $(0.0051)$ & $-0.0134 * * *$ & $(0.0051)$ \\
\hline AFP Prima & $0.0261 * * *$ & $(0.0055)$ & $0.0260 * * *$ & $(0.0055)$ \\
\hline AFP Habitat & $-0.0656^{*}$ & $(0.0342)$ & $-0.0705 * *$ & $(0.0342)$ \\
\hline Fund type 1 (low-risk) & $-0.0480 * * *$ & $(0.0136)$ & & \\
\hline Fund type 3 (high-risk) & $0.0197 * *$ & $(0.0088)$ & & \\
\hline Active portfolio management & & & $0.0230 * * *$ & $(0.0085)$ \\
\hline pseudo R2 & 0.211 & & 0.211 & \\
\hline $\mathrm{N}$ & 64,588 & & 64,588 & \\
\hline
\end{tabular}

Note: The dependent variable takes value one if the individual chose the load factor fee and zero otherwise. The coefficients are the marginal effects of probit regressions. All regressions include regional fixed effects. The reference category for the balance and income quintiles is the first quintile, for self-employed is employee, for the fund administrators is AFP Integra, and for the fund type is the fund type 2 (moderate). Robust standard errors are in parentheses. ${ }^{*} \mathrm{p}<0.10,{ }^{*} \mathrm{p}<0.05, * * * \mathrm{p}<0.01$.

Both models of Table 3 report quite similar results, but we prefer to focus on the second specification as it includes the proxy for financial literacy. The results show that individuals who are female, older and self-employed are more likely to choose the load factor fee. Contribution density is a very important determinant of choosing this type of fee. For example, an increase of 10 percent in contribution density is associated with an increase of 6.2 percentage points in the 
probability of choosing the load factor fee. This choice is positively associated with the position of the individual in the distributions of income and savings balance. So, income-rich or pension balance-rich individuals are more likely to choose the load factor fee. The position within the pension balance distribution has a more sizable effect than that of the income distribution. For example, moving from the first to the fifth quintile of income increases the probability of choosing the load factor fee by 6.4 percentage points, while this effect is 23.3 percentage points for the same quintiles of the pension balance distribution. Moreover, being active in the risk management of the one's own pension fund is associated with an increase of 2.3 percentage in the likelihood of choosing the load factor fee. This may indicate that individuals with more financial literacy are more likely to choose the load factor fee, thus opting out of the default. ${ }^{13}$

\subsection{The extent of gains and losses}

Although we find that a large share of individuals lose money in their current fee schemes, we also assess the intensity of these losses and whether some gains exist. As explained in Section 4.2 , the difference in charge ratios $\left(\Delta_{m l}\right)$ indicate the degree of gains or losses in terms of the percentage change in the final pension balance. Figure 3 shows the cumulative distribution of this variable by type of fee in order to illustrate the intensity of gains and losses. The thin blue line shows the cumulative distribution for individuals assigned to the balance fee, and the thick red line represents the cumulative distribution for the individuals who chose the load factor fee.

The figure shows that the intensity of the loss is very high for those who chose the balance fee. On the contrary, gains are considerably lower. For example, 20.2 percent of these individuals will lose between 10 and 15 percent of their final pension balance, and about 4.1 percent will lose more than 15 percent. Among the individuals assigned to the balance fee, the average size of the change in pension balance is -7.0 percent for those who lose, 0.9 percent for those who gain and -5.9 percent for all individuals. In contrast, as shown in Figure 3, the losses among the individuals who opted for the load factor fee are less severe. On average, the size of the change in the pension balance is -1.3 percent for those who lose, 3.6 percent for those who gain and 1.4 percent for all the individuals in this scheme.

\footnotetext{
${ }^{13}$ It is worth noting that, in model 1, having a low-risk fund (fund type 1) or a higher-risk fund (fund type 3 ) are associated with a decrease of 4.8 percentage points and an increase of 2.0 percentage points, respectively, in the probability of choosing the load factor fee. So, the individuals that are more willing to take risk are more likely to choose the load factor fee.
} 
Figure 3: Cumulative Gains/Losses due to Fee Scheme

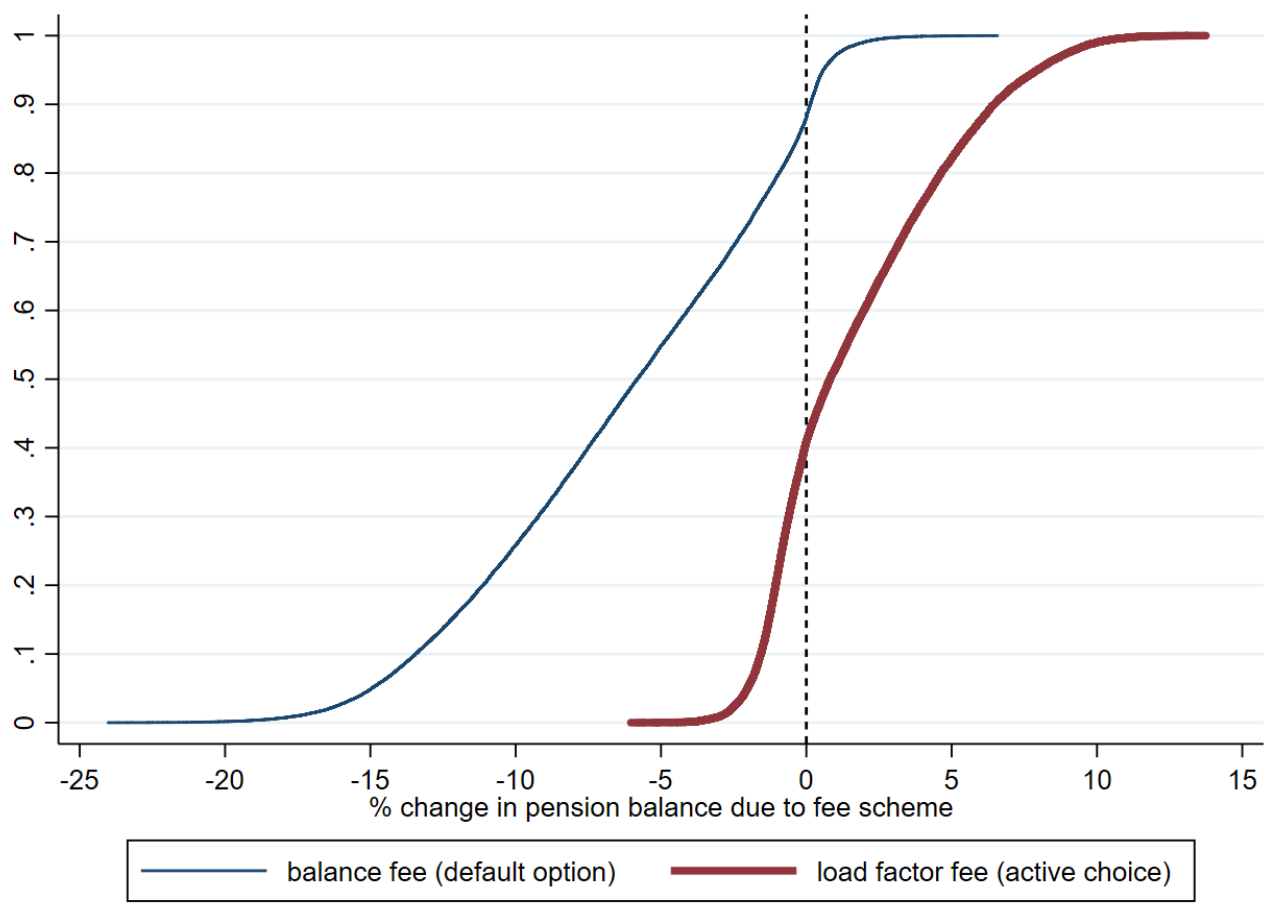

Losses and gains vary largely over age. As Table 4 shows, young individuals (those below 40 years old) with the default balance fee are the main losers of the reform. Choosing this scheme means that these individuals pay more to the AFP itself, resulting in lower pension balances. For example, all individuals in the 21-25 age group lose money, and their pension balances are reduced 13.6 percent, while the 51-55 age group is less affected because only 34 percent lose money and their balances are reduced by much less (1.4 percent). Table 4 also shows the losses and gains for individuals who opted for the load factor fee. In this case, individuals above 45 years old lose more but the change in their pension balances ranges between -1.4 and -0.9 percent.

Tables A.8, A.9 and A.10 in the appendix provide additional results by quintiles of income, density of contribution and pension balance. The main result is that independent of the quintile, a significant proportion (around 86 percent) of individuals assigned to the balance fee are worse off financially due to the reform. Their retirement savings have been reduced by around 7.0 percent. 


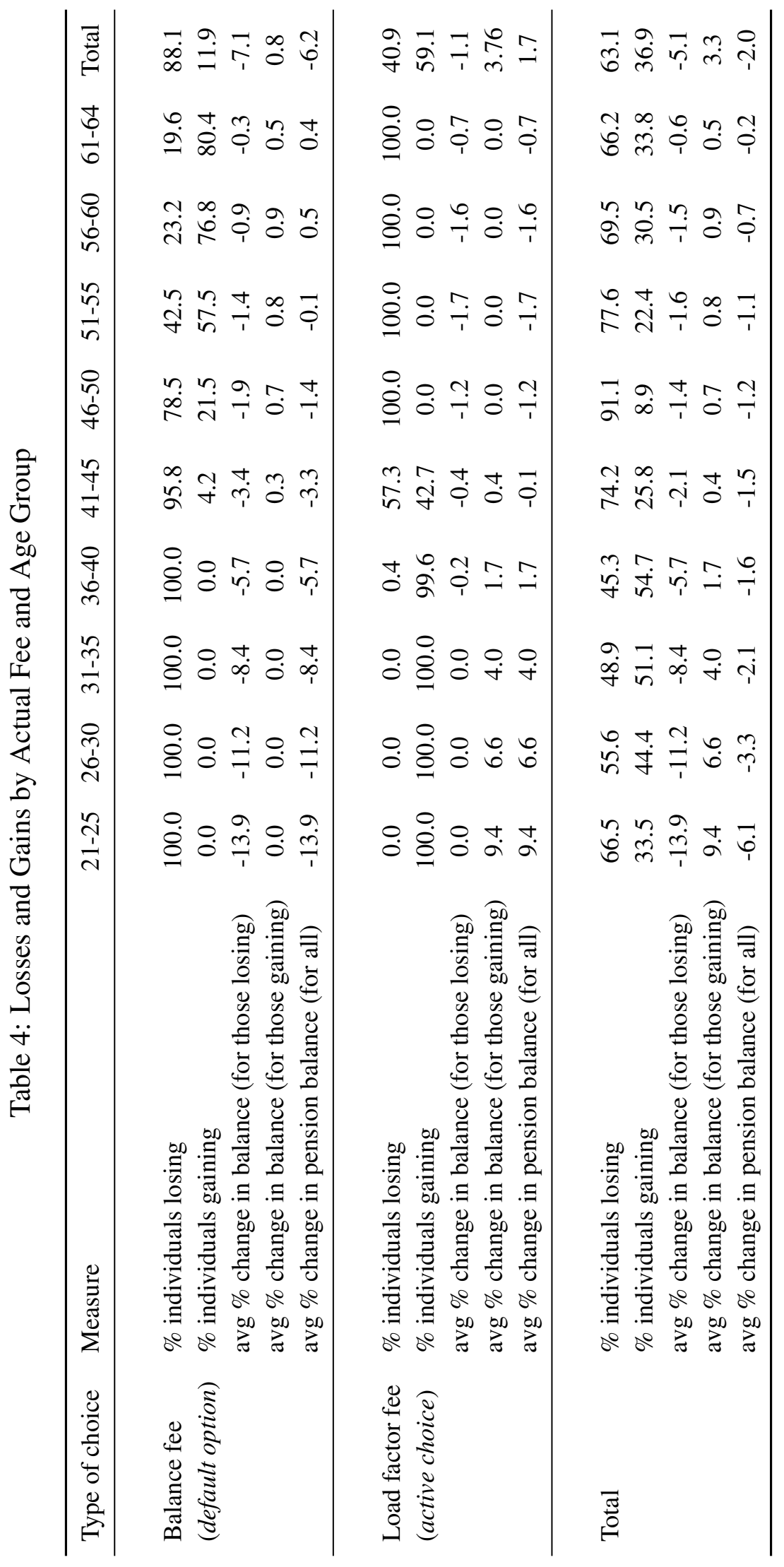




\subsection{Determinants of choosing well}

In this section we analyze the main determinants of choosing the fee scheme that best serve the interests of the individuals. Table 5 displays the results. The first set of results shows the marginal effects of a probit model where the dependent variable equals one if the individual has the fee scheme with the lower change ratio, and zero otherwise. Males are slightly less likely to make a good choice. Being male reduces the likelihood of making a good decision by 3.1 percentage points. With each additional year in an individual's age, we see a reduction of 0.5 percentage points in the likelihood that individual made a good choice. Although this is a small effect for one extra year, we observe important differences between young and old individuals. For example, the probability of choosing the right fee scheme is about 13.5 percent higher for a 25-year-old than for a 55-year-old. Contribution density and self-employment, along with the quintile in the pension balance distribution, are positively associated with the likelihood of making a good choice, but the effect of the income position is less clear or less precisely estimated. For example, moving from the first to the fifth quintile of the pension balance distribution boosts the probability of making a good choice by 25.6 percentage points. Furthermore, being active in portfolio management - our proxy for financial literacy - increases the likelihood of making a good choice by 3.3 percentage points.

The second set of results in Table 5 shows the OLS estimates of the percentage change in the pension balance $\left(\Delta_{m l}\right)$. Age and contribution density are two of the most important variables that determine the size of the gains and losses. For example, moving from the second to the third quintile of the age distribution (from age 39 to 47) is associated with a percentage change of 0.99 in the pension balance. Similarly, moving from the second to the third quintile of the distribution of contribution density is associated with an increase of 0.84 percentage points in the pension balance. Further, a higher position in the pension balance distribution, and being self-employed, are also associated with larger gains. However, having spent more years enrolled in the SPP is related with higher losses. Being active in portfolio management is associated with gains of 0.18 percentage points. In summary, the policy reform seems to produce higher losses for individuals who are younger, male and employees, and who have low pension balances, contribute less often, have spent more years in the SPP and are less active in the management of their pension funds. 
Table 5: Determinants of Choosing the Best Fee and Estimates for Losses/Gains in Pension Balance

\begin{tabular}{|c|c|c|c|c|}
\hline & \multicolumn{2}{|c|}{$\begin{array}{l}\text { Dep var: the individual chose } \\
\text { the better fee scheme (Probit } \\
\text { ME) }\end{array}$} & \multicolumn{2}{|c|}{$\begin{array}{l}\text { Dep var: percentage change in } \\
\text { pension balance due to fee } \\
\text { scheme (OLS) }\end{array}$} \\
\hline & Coef. & S.E. & Coef. & S.E. \\
\hline Male & $-0.0314 * * *$ & $(0.0041)$ & $-0.6844 * * *$ & $(0.0453)$ \\
\hline Age & $-0.0045 * * *$ & $(0.0004)$ & $0.1240 * * *$ & $(0.0028)$ \\
\hline Contribution density & $0.2414 * * *$ & $(0.0107)$ & $3.2570 * * *$ & $(0.0978)$ \\
\hline Pension balance - 2 nd quintile & $0.0977 * * *$ & $(0.0079)$ & $1.1981 * * *$ & $(0.0784)$ \\
\hline Pension balance - 3th quintile & $0.1786^{* * *}$ & $(0.0093)$ & $2.2348 * * *$ & $(0.0935)$ \\
\hline Pension balance - 4th quintile & $0.2242 * * *$ & $(0.0105)$ & $2.8731 * * *$ & $(0.1031)$ \\
\hline Pension balance - 5th quintile & $0.2560 * * *$ & $(0.0122)$ & $3.3183^{* * *}$ & $(0.1191)$ \\
\hline Income - 2nd quintile & $-0.0235 * * *$ & $(0.0065)$ & $-0.4081 * * *$ & $(0.0683)$ \\
\hline Income - 3th quintile & 0.0012 & $(0.0067)$ & -0.0456 & $(0.0687)$ \\
\hline Income - 4th quintile & -0.0085 & $(0.0069)$ & -0.0005 & $(0.0718)$ \\
\hline Income - 5th quintile & -0.0046 & $(0.0078)$ & -0.0091 & $(0.0839)$ \\
\hline Self-employed & $0.0389 * * *$ & $(0.0131)$ & $0.6404 * * *$ & $(0.1096)$ \\
\hline Years enrolled in SPP & $-0.0151 * * *$ & $(0.0006)$ & $-0.0920 * * *$ & $(0.0045)$ \\
\hline AFP Profuturo & $-0.0233 * * *$ & $(0.0047)$ & -0.0673 & $(0.0471)$ \\
\hline AFP Prima & $0.0269 * * *$ & $(0.0049)$ & $0.2950 * * *$ & $(0.0552)$ \\
\hline AFP Habitat & $-0.0550 * *$ & $(0.0277)$ & -0.6471 & $(0.4020)$ \\
\hline Active portfolio management & $0.0325 * * *$ & $(0.0074)$ & $0.1848 * * *$ & $(0.0549)$ \\
\hline Constant & & & $-10.2416^{* * * *}$ & $(0.2853)$ \\
\hline $\mathrm{R} 2$ & 0.1014 & & 0.1698 & \\
\hline $\mathrm{N}$ & 64588 & & 64588 & \\
\hline
\end{tabular}

Notes: All regressions include regional fixed effects. The reference category for the balance and income quintiles is the first quintile, for self-employed is employee and for the fund administrators is AFP Integra. Robust standard errors are in parentheses. $* \mathrm{p}<0.10, * * \mathrm{p}<0.05, * * * \mathrm{p}<0.01$.

From Table 2 we observe that, among the individuals who chose to remain in the load factor fee, 59.1 percent made the best choice (i.e., $\lambda^{l}<\lambda^{m}$ for them) and 40.9 percent did not. The default balance fee is the best option for only 11.9 percent of the people who currently have it (i.e., $\lambda^{l}>\lambda^{m}$ for them) and is less advantageous for the other 81.1 percent. Why is the default fee such a bad option for such a large group of people? The inspection of predicted conditional probabilities that the load factor is the best option (see Figure A.1 in the appendix) reveals an important relationship between making a good choice and age. In the group who chose the load factor fee, this option is the best for younger individuals (up to age 37) but is a bad choice for older individuals (aged 47 and up). Similarly, among the individuals who have the default balance fee, the load factor fee is instead the best option for younger individuals; from age 37, the probability of the load factor being better starts to decrease (e.g., at 53 this probability is about 0.5 ). One of the main reasons why the load factor fee may be better than the balance fee at younger ages is that this fee (applied over a longer period of capitalization up to retirement) 
does not reduce the pension balance as much as the balance fee would. In contrast, the balance fee may be better for older individuals as the capitalization period up to retirement is shorter and therefore the reduction of the pension balance will be less important.

Given the strong relevance of age, one may ask why the government did not design the default option including conditions by age or the possibility that individuals can opt out. For those who chose to remain in the load fee, one can argue that they should assume the consequences of their active, though sub-optimal, decisions. However, what can we argue for individuals who involuntarily accepted the default and were adversely affected?. ${ }^{14}$

The other panels of Figure A.1 in the appendix reveal a positive, although weak, relationship between the probability that the load factor fee is the best option and income and pension balance.

\section{Sensitivity checks}

\subsection{Different values of the balance fee}

To simulate individual pension balances, we use the actual balance fees of each AFP and assume that they do not change during the simulation period (1.20 percent for Integra and Profuturo, and 1.25 percent for Prima and Habitat, i.e. an average of 1.23 percent). As the level of fees determines whether one fee scheme is better than the other, we check our main results in three additional scenarios. In doing so, we do not change the levels of the load factor fees; instead, we focus on the balance fees as they have prompted intense debate during the reform period. These scenarios are as follows: i) the balance fee is set at 1.00 percent for the whole period; ii) the balance fee is set at 0.75 percent for the whole period; and iii) the balance decreases over time.

Although assuming a scenario of declining balance fees is quite optimistic in a market with just four providers and minimal change in prices (see Figure 2b), it is still important to assess whether this scenario would cause the relative proportions of losers and winners to change and whether the intensities of the losses and gains vary. The assumed reduction of balance fees closely follows the expected trajectory of these fees outlined by the SBS in their motivations for reform (appendix of Regulation SBS N ${ }^{\circ}$ 8514-2012). Based on these projections, the balance fees would have started to decrease in 2017, reaching 0.6 percent for all individuals by 2036 and remaining there indefinitely. ${ }^{15}$

\footnotetext{
${ }^{14}$ See Dobrescu et al. (2016) for more details on how poorly designed default options - particularly the irreversible ones - can severely affect retirement savings.

${ }^{15}$ To estimate the long-term fee of 0.6 percent, the SBS assumes that the AFP will charge a balance fee that allows them to obtain, on average, similar fee revenues as were obtained before the reform with the load factor fee (see the methodological appendix of Regulation SBS N 8514-2012). As the pension balance increases over time, the balance fee needs to decrease. The SBS assumed that the reduction would occur in three periods: in period 1 (the first 10 years after the reform), each AFP charges different market prices; in period 2 (from year 11 to year 20), the fee level is assumed to be 1.6 times $0.6 \%$; and in period 3 (from year 21 to year 30 ) when the balance fee
} 
Table 6 summarizes our results. As expected, a lower balance fee increases the percentage of individuals that are better off (winners) with the balance fee. In the baseline scenario, this percentage is only 5.6 percent, but in scenarios where the balance fee is lower (for example 1.0 or 0.75 percent or in the decreasing fee) the percentage increases to $9.1,17.9$ and 15.9 percent, respectively. Accordingly, the fraction of winners under the load factor fee decreases from 31.3 to $23.7,8.7$ and 4.3 percent, respectively. Table 6 also shows that in the baseline scenario, the losers with the balance fee represent 41.4 percent of the sample, but in scenarios 1, 2 and 3 they represent 37.9, 29.1 and 31.1 percent, respectively. So, even in a very optimistic scenario (fee of 0.75 percent) with a relatively low balance fee, more than one quarter of the sample (29.1 percent) is still worse off with the default balance fee. This amount of losers is still greater than the amount of winners with the balance fee (17.9 percent). For those who opted for the load factor fee, the scenarios with lower balance fees naturally imply that they are worse off as they are enrolled in a relatively more expensive scheme. The fraction of losers who would be better off with the balance fee increases from 21.7 to $29.3,44.3$ and 48.7 percent for the scenarios 1 , 2 and 3.

A reduction in the balance fee is always good news for individuals, but we observe an increase in the overall number of losers from 63.0 to $67.1,73.4$ or 79.8 percent under the scenarios 1,2 and 3, respectively. The reason is that individuals cannot switch between fee schemes, so those who chose the load factor fee are locked up in a relatively more expensive scheme. This is a sort of policy trap established by the reform: reductions in the balance fees (relative to load fees) cannot be taken advantage of by the individuals who actively chose to remain in the load fee. The only way to allow all individuals to benefit from reductions in the balance fee would be allowing them to change their choice of fee.

would reach $0.6 \%$. In our simulation, we make a slight change: we begin the balance fee reduction in 2016 , then follow the criteria of periods 2 and 3. Thus, we reach the long-term balance fee in 2036. 
Table 6: Type of Choice under Different Values of Balance Fee (\% of total individuals)

\begin{tabular}{lcccc}
\hline Type of choice & $\begin{array}{c}\text { Baseline } \\
\text { Balance fee } \\
=1.23 \%\end{array}$ & $\begin{array}{c}\text { Scenario 1 } \\
\text { Balance fee } \\
=1.00 \%\end{array}$ & $\begin{array}{c}\text { Scenario 2 } \\
\text { Balance fee } \\
=0.75 \%\end{array}$ & $\begin{array}{c}\text { Scenario 3 } \\
\text { Decreasing } \\
\text { balance fee }\end{array}$ \\
\hline a. Balance fee is better \& balance fee is chosen & 5.6 & 9.1 & 17.9 & 15.9 \\
b. Load factor fee is better \& load fee is chosen & 31.3 & 23.7 & 8.7 & 4.3 \\
Total of individuals with right choice $(\mathrm{a}+\mathrm{b})$ & 36.9 & 32.9 & 26.6 & 20.2 \\
& & 37.9 & 29.1 & 31.1 \\
c. Load factor fee is better \& balance fee is chosen & 41.4 & 29.3 & 44.3 & 48.7 \\
d. Balance fee is better \& load fee is chosen & 21.7 & 67.1 & 73.4 & 79.8 \\
Total of individuals with wrong choice (c+d) & 63.1 & & 100.0 & 100.0 \\
Total & & 100.0 & 100.0 & 100.0 \\
\hline
\end{tabular}

Note: The baseline scenario uses the balance fees of each AFP through the simulation period: 1.20 percent for Integra and Profuturo, and 1.25 percent for Prima and Habitat (so, an average of 1.23 percent). Scenarios 1 and 2 utilize the balance fees 1.0 and 0.75 percent for all AFP through the simulation period. Scenario 3 uses a descending balance fee through the simulation period: it decreases until 2036, when it reaches 0.6 percent for all AFP and remains at this value for the rest of the simulation period (this follows the methodological appendix of the regulation SBS N $N^{\circ} 8514-2012$ established by the SBS in order pass the fee reform in the Parliament).

Figures A.2, A.3 and A.4 in the appendix show the cumulative distribution of gains and losses in terms of the percentage change in the final pension balance for each scenario considered. The intensity of the losses is smaller for the individuals who chose the balance fee in comparison to the distribution shown in Figure 3, especially in the scenario of a 0.75 percent balance fee. The gains are also greater in this scenario, as expected. Consequently, the losses among individuals who opted for the load factor fee increase, which indicates they will have relatively lower pension balances. Table A.12 in the appendix shows that, while the average loss in the baseline scenario is -7.1 percent for the losers in the default balance fee scheme, it is -3.1 and -2.6 percent in the scenarios with a balance fee of 0.75 percent and with decreasing fees, respectively. Similarly, the average gains for the individuals who benefit from choosing the load factor fee reduce from 3.7 percent to 1.2 and 0.8 percent in scenarios 2 and 3, respectively. Moreover, the composition of the individuals who gain or lose changes with different levels of balance fees. For example, among the individuals who rightly chose the fee scheme in the baseline scenario, 62 percent are males and have an average age of 37.2, whereas in the scenario with decreasing fees, the individuals who chose best are 67 percent male and have an average age of 41.8. The opposite trends occur among the individuals the less optimal fee scheme. Thus, all else equal, a decrease in balance fees may be more beneficial for males and older people. Table A.12 in the appendix reports more average individual characteristics by distinctive scenarios.

In summary, the analysis presented in this section suggests that first, the relative proportions of losers and winners change with the level of the balance fees. The fraction of winners (losers) with the balance fee increases with a lower (higher) fee. Second, the intensities of the losses and gains for individuals assigned to the balance fee vary when the fee is lower. The intensity of 
the loss reduces and the intensity of the gains increases. However, an open question is whether balance fees can decrease over time to reach 0.60 percent on average (our third scenario, which resembles the fees values assumed by the policy makers during the reform) given the current levels of 1.23 percent, especially in a mandatory IRA system with just four providers.

\subsection{Potential effects on inequality}

The study of the distribution of wealth has received a renewed interest thanks to the emergence of new data (Saez and Zucman (2016), Piketty and Zucman (2015)) and developments in its measurement (Cowell and Van Kerm (2015), Davies et al. (2017), Cowell et al. (2017)). Because pension balances are part of household wealth portfolios, we can assess whether the reform has any effect on one of the important components of wealth. For this aim we use Gini-Recentered Influence Function (RIF-Gini) regressions to uncover the predictors of the inequality in pension balances (Firpo et al. (2009) and Choe and Van Kerm (2018)). This method allows us to compute how much would a small change in one covariate could affect the Gini index (or any other inequality statistic). The key covariate that we investigate is the fee scheme chosen by the individual. There are two stages in the RIF regressions. First, the influence function (IF) (Hampel et al. (1986)) of each individual on the pension balance distribution is computed. This computation means that we can estimate the influence of each individual on the Gini index of pension balances as a function of her own pension balance and of the overall distribution of pension balances. In the second stage, the computed Gini IF is linearly regressed against some covariates of interest. For example, a positive coefficient for the balance fee (a dummy variable) means that marginally increasing the share of individuals with this fee - and assuming that the distribution of all the other covariates are constant - would lead to an increase in the Gini index. The size of this coefficient indicates the size of the increase in the Gini index if all individuals chose the balance fee. ${ }^{16}$

The $I F$ and Gini index are computed with the final pension balance (at age 65) simulated for each individual, taking into account her actual fee scheme. In order to reduce the role of lifecycle effects due to the paths of accumulation for pension balances, we compute Gini indexes for different age groups. Equation 8 shows the specification model of RIF-Gini regressions for a particular cohort. The dependent variable is the influence function (IF, previously estimated in the first stage) of each individual divided by the Gini index of he corresponding cohort's pension balances. The covariates $\left(X_{i}\right)$ are sex, age, contribution density, income, initial pension balance, labor status, time enrolled in SPP, fund administrator, fund type and regional fixed effects; balance fee equals one if the individual chose the balance fee and zero otherwise.

$$
I F_{i}=\alpha+\beta_{1} X_{i}+\beta_{2} \text { balancefee }_{i}+\varepsilon_{i}
$$

\footnotetext{
${ }^{16}$ Although we focus on the Gini index due to its popularity and normative properties, there are other IF types useful for distribution analysis (see Essama-Nssah and Lambert (2012), Davies et al. (2017)).
} 
The first set of results in Table 7 presents the coefficients estimated for balance fee for each cohort group (the estimates of all covariates are in Table A.13 in the appendix). The coefficients represent percentage changes. For example, the coefficient 0.1177 for the cohort group 26-30 indicates that an increase of 1 percent in the proportion of individuals with the balance fee is associated with an increase of 0.12 percent in the Gini index of pension wealth. When statistically significant, the effect on the inequality of the balance fee scheme is positive and ranges between 0.06 percent and 0.14 percent. Therefore, another potential impact of the pension reform is a future increase in pension wealth inequality. This result can be explained by the fact that balance fees penalize the accumulation of funds, particularly the funds of individuals who have both a low income and a low contribution density; this then enlarges the wealth gap between individuals.

Table 7: Influence of Balance Fee and Financial Literacy on Pension Wealth Inequality

\begin{tabular}{|c|c|c|c|c|c|}
\hline \multirow[t]{2}{*}{$\begin{array}{l}\text { Age group } \\
\text { regression }\end{array}$} & \multirow[t]{2}{*}{ Gini index } & \multicolumn{2}{|c|}{$\begin{array}{l}\text { RIF Gini coefficient for } \\
\text { balance fee }\end{array}$} & \multicolumn{2}{|c|}{$\begin{array}{l}\text { RIF Gini coefficient for } \\
\text { active portfolio } \\
\text { management }\end{array}$} \\
\hline & & Coef & S.E. & Coef & S.E. \\
\hline $21-25$ & 0.5515 & -0.0230 & $(0.0202)$ & -0.0727 & $(0.1234)$ \\
\hline $26-30$ & 0.5977 & $0.1177 * * *$ & $(0.0155)$ & 0.0103 & $(0.0469)$ \\
\hline $31-35$ & 0.5911 & $0.1379 * * *$ & $(0.0110)$ & -0.0140 & $(0.0227)$ \\
\hline $36-40$ & 0.6018 & $0.1131 * * *$ & $(0.0124)$ & $-0.0894 * * *$ & $(0.0234)$ \\
\hline $41-45$ & 0.6156 & $0.0908 * * *$ & $(0.0101)$ & $-0.1501 * * *$ & $(0.0279)$ \\
\hline $46-50$ & 0.6187 & $0.0827 * * *$ & $(0.0113)$ & $-0.1465 * * *$ & $(0.0271)$ \\
\hline $51-55$ & 0.6283 & $0.0657 * * *$ & $(0.0162)$ & $-0.2350 * * *$ & $(0.0449)$ \\
\hline $56-60$ & 0.6440 & 0.0233 & $(0.0169)$ & $-0.1138 * * *$ & $(0.0396)$ \\
\hline $61-65$ & 0.6655 & $0.0561 * *$ & $(0.0229)$ & -0.1413 & $(0.0969)$ \\
\hline
\end{tabular}

Note: Each row corresponds to a regression for an age group. The dependent variable is the Influence Function (IF) of each individual in the Gini of final pension balance in each age group divided by the Gini index of the corresponding age group. All regressions include region fixed effects, sex, age, contribution density, labor status, time enrolled in SPP, fund administrator, income and initial pension balance. Robust standard errors are reported in parenthesis. $* * * \mathrm{p}<0.01, * * \mathrm{p}<0.05, * \mathrm{p}<0.10$.

Another interesting result drawn from the RIF-Gini approach (the second set of results of Table 7) is the measurement of financial literacy's potential impact on pension wealth inequality in an IRA system. For instance, Lusardi et al. (2017) find in the US that about 30-40 percent of retirement wealth inequality is determined by differences in financial literacy. Financial knowledge may allow individuals to better allocate lifetime resources under uncertainty. The RIF-Gini coefficients for Active portfolio management, when statistically significant, indicate that an increase in the proportion of individuals actively managing their portfolios (arguably with more financial literacy) may reduce pension wealth inequality. 


\subsection{Varying discount interest rates}

The key feature of the charge ratio criterion used so far is that it reveals which scheme allows an individual to obtain a higher final pension fund relative to the invested amount. However, it does not take into account individual preferences for consumption. If individuals dislike postponing consumption, then the choice for the load factor fee may be less appealing as this involves a slightly higher share of contributions (pension contribution rate plus load factor fee) than the balance fee, which only includes the pension contribution rate. We use an indirect utility approach to assess whether the actual choice made by the individual corresponds to the fee scheme that generates the higher utility. In doing so, we utilize alternative values of discount interest rates in order to examine to what extent the choice of the individual is also the optimal choice for each of these interest rates.

The individual derives utility from consumption, and we assume that the utility function is separable in consumption over time. As in Kotlikoff and Spivak (1981), we use the expected utility of consumption streams weighted by survival probability. The individual maximizes the expected utility at current age $x$ (equation 9) subject to a budget constraint (equation 10):

$$
\begin{gathered}
E U=\sum_{t=0}^{D-x} p_{x_{t}} \beta^{t} U\left(C_{t}\right) \\
\sum_{t=0}^{D-x} p_{x_{t}} C_{t} R^{-t}=W_{0}=\sum_{t=0}^{65-x-1}\left[y_{t} R^{-t}\right]+\sum_{t=65-x}^{D-x}\left[P_{t} R^{-t}\right]
\end{gathered}
$$

$D$ is the maximum survival age, $C_{t}$ is the consumption in time $t, \delta$ is the subjective rate of time preference (with $\beta=1 /(1+\delta)$ ), $p_{x_{t}}$ is the probability of survival from age $x$ to age $x+t$, and $R=(1+r)$ where $r$ is the discount interest rate. In the budget constraint of equation 10 , the consumption plan must be financed with $W_{0}$, which captures all the resource streams of the individual (wages $y_{t}$ and pensions $P_{t}$ ) discounted with the interest rate $r$. There are no bequests, so that the individual consumes all her resources until death. We assume the iso-elastic utility function $U\left(C_{t}\right)=\frac{C_{t}^{1-\gamma}}{1-\gamma}$ where $\gamma$ is the parameter of risk aversion (assuming $\gamma<1$ ). Given that the discounted resources included in $W_{0}$ are different under the two fee schemes, we distinguish $W_{0}^{l}$ and $W_{0}^{m}$ for the load and balance fees. The indirect utilities obtained with the load factor $(V()$.$) and balance fees (H()$.$) can be compared in order to determine which fee attains more$ utility for the individual. To this end, it is enough to examine whether $\left(W_{0}^{l} / W_{0}^{m}\right)^{1-\gamma}$ is greater of less than one. To establish that the load factor fee is better than the balance fee, $W_{0}^{l}$ must simply be greater than $W_{0}^{m}$ (all the steps and details are described in the Appendix).

We use 1,000 values of discount interest rates to generate different values for $W_{0}^{l}$ and $W_{0}^{m}$ and, subsequently, to find whether the load factor or the balance generates more utility for the individual conditional on the value of the interest rate. Then, we can assess if this optimal choice corresponds with individual's current fee. Figure 4 plots the share of individuals whose actual fee scheme corresponds to the one attaining the largest indirect utility, computed with 
different values of discount interest rates. We observe that the level of interest rates does not significantly affect the share of individuals choosing the optimal fee. Between 52 and 55 percent of individuals are actually in the fee scheme associated with more utility; this does not change much when we utilize distinctive scenarios of pension fund simulation. Although this approach reports a larger share of people with the more advantageous fees than does the charge ratio criterion (36.9 percent), about half of the individuals still have the worse fee. We also observe that the share of individuals who have chosen well is larger among the group of people who chose the load factor fee than in the group with the balance fee (See Figure A.5 in the appendix). As expected, the advantages of the load factor fee decrease with the discount interest rate (up to a certain level), while the opposite occurs with the balance fee, at least until the interest rate reaches 18 percent (also in Figure A.5).

Figure 4: Share of Individuals with the Better Fee by Discount Interest Rate and Distinctive Scenarios

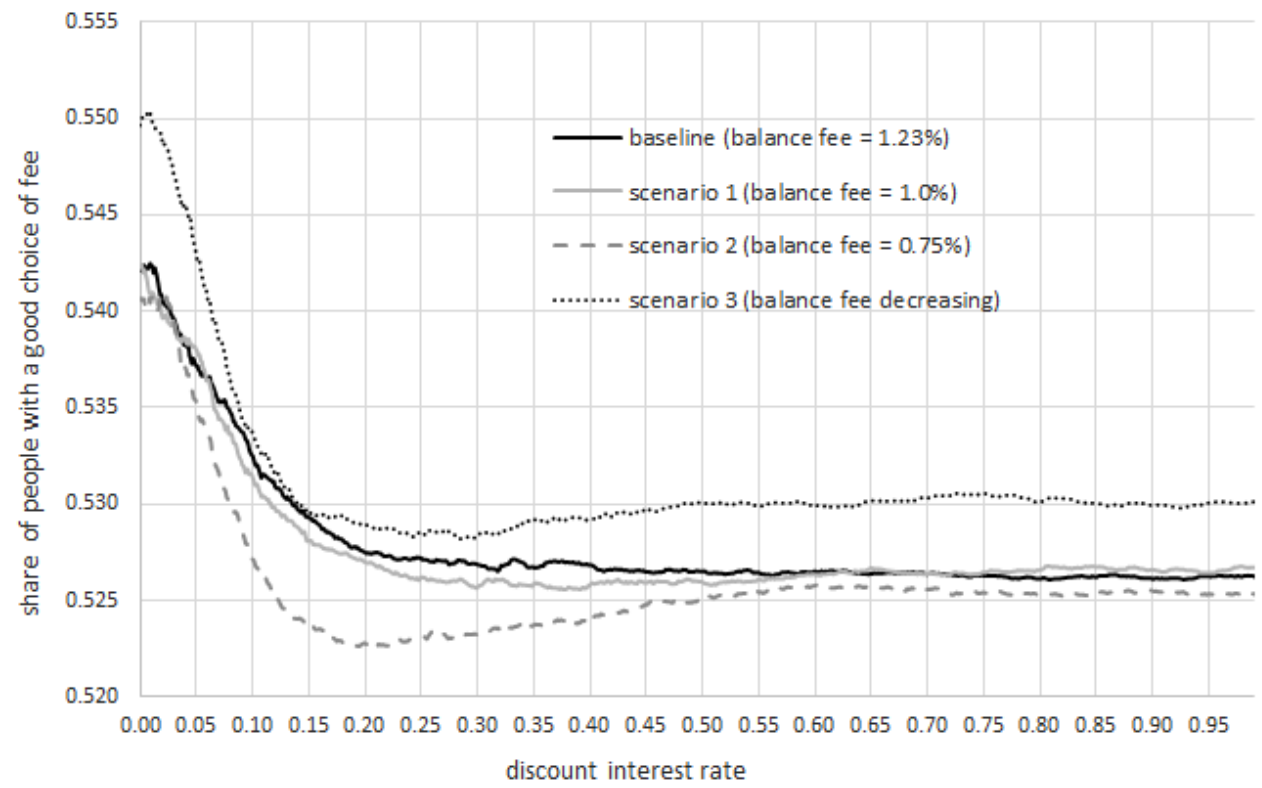

Note: This graph plots the share of individuals whose actual fee scheme corresponds to the one attaining the largest indirect utility computed with different values of discount interest rates. The graph shows the results for the baseline pension fund simulation and other three scenarios with lower balance fees.

\section{Conclusions}

One of the main lessons from our study is that governments should carefully design pension policies, and take into consideration market limitations and financial literacy levels, particularly when including an irreversible default option. In pension systems, mistakes made by individuals have irreversible and long-term consequences. We show that the reform of pension fund fees implemented in Peru in 2013 has had, and will continue to have, adverse effects on pension wealth. The reform established a new balance fee that is a percentage of the pension balance. 
Individuals could also opt to stay with the previous fee, a load factor fee that is a percentage of their salary. Our results indicate that the reform adversely affects the pension wealth of 63.1 percent of individuals. This percentage is composed of 41.4 percent of individuals who were assigned or chose the balance fee and 21.7 percent who freely chose the load factor fee. We also find an important relationship between making a good choice and age. The load fee seems quite good option for young individuals, whereas a balance fee is not. However, the government did not take this into account.

Our data set composed of individual administrative records does not include direct measures of financial literacy, but we are able to capture this feature by constructing a measure of how actively individuals manage their pension fund portfolios. The results suggest that financial literacy plays an important role in making sound decisions about pension fund fees. Unfortunately, Peru has very low levels of financial literacy and this limitation was not taken into account in the policy design.

We also perform some robustness checks and find that the individuals who chose the balance fee are better off as the fee decreases. However, even when the reduction of balance fees is good news, we observe that this fee may also increase the overall number of people who lose due to the reform. This means that the policy has inadvertently established a trap: potential reductions in the balance fees (relative to load fees) cannot be taken advantage of by the individuals who actively chose the load fee. Therefore, if a hypothetical reduction in balance fees occurs, the government should consider encouraging a shift from the load factor to the balance fee for certain individuals.

We also observe large heterogeneity in the intensities of losses and gains due to the reform, where the losses are larger than the gains. In particular, younger and poorer individuals, and those with the balance fees show higher losses. Moreover, we use Gini-Recentered Influence Function regressions and find that the policy change in the fee scheme is associated with increasing inequality in pension wealth. Interestingly, increasing the share of individuals who are financially literate may reduce pension wealth inequality.

In general, our findings contrast with some assumptions made during the reform's implementation. One assumption was that private pension managers will have incentives (aligned interests) to perform better since they can directly charge their management fees to the pension balance instead of to salaries, which would lead to higher rates of returns for both individuals and providers. However, this assumption seems overly confident in a market with just four providers and minimal change in prices over time. Another implicit assumption was that the default option is the best for all individuals, given that it is irreversible. Nevertheless, our results show that this is not necessarily the case. 


\section{References}

Aguila, E., Hurd, M., and Rohwedder, S. (2014). How do management fees affect retirement wealth under mexico's personal retirement account system? Latin American Policy, 5(2):331-350.

Alonso, J., Sánchez, R., and Tuesta, D. (2014). Un modelo para el sistema de pensiones en el perú: Diagnóstico y recomendaciones. Revista Estudios Económicos, 27:81-98.

Banks, J., Crawford, R., and Tetlow, G. (2015). Annuity choices and income drawdown: evidence from the decumulation phase of defined contribution pensions in england. Journal of Pension Economics and Finance, 14(4):412-438.

Beshears, J., Choi, J., Laibson, D., and Madrian, B. (2008). How are preferences revealed? Journal of Public Economics, 92(8-9):1787-1794.

Carroll, G., Choi, J., Laibson, D., Madrian, B., and Metrick, A. (2009). Optimal defaults and active decisions. QJ Econ., 1(124(4)):1639-1674.

Chávez-Bedoya, L. (2017). The effects of risk aversion and density of contribution on comparisons of administrative charges in individual account pension systems. Journal of Pension Economics and Finance, 16(1):1-20.

Choe, C. and Van Kerm, P. (2018). Foreign workers and the wage distribution: What does the influence function reveal? Econometrics 2018, 6(41).

Cowell, F., Nolan, B., Olivera, J., and Van Kerm, P. (2017). Wealth, top incomes and inequality. National Wealth: What is missing, why it matters, pages 175-206.

Cowell, F. and Van Kerm, P. (2015). Wealth inequality: A survey. Journal of Economic Surveys, 29(4):671-710.

Davies, J., Fortin, N., and Lemieux, T. (2017). Wealth inequality: Theory, measurement and decomposition. Canadian Journal of Economics, 50(5):1224-1261.

Dobrescu, L., Fan, X., Bateman, H., Newell, B., Ortmann, A., and Thorp, S. (2016). Retirement savings: A tale of decisions and defaults. The Economic Journal, 128:1047-1094.

Dobronogov, A. and Murthi, M. (2005). Administrative fees and costs of mandatory private pensions in transition economies. Journal of Pension Economics and Finance, 4(1):31-55.

Essama-Nssah, B. and Lambert, P. (2012). Influence functions for policy impact analysis. Inequality, mobility and segregation: Essays in honor of Jacques Silber, 50(5):135-159.

Firpo, S., Fortin, N., and Lemieux, T. (2009). Unconditional quantile regressions. Econometrica, 77(3):953-973.

Gallo, G., Torricelli, C., and van Soest, A. (2018). Individual heterogeneity and pension choices: Evidence from italy. Journal of Economic Behavior \& Organization, 148:260-281.

Goda, G. and Flaherty, C. (2013). Incorporating employee heterogeneity into default rules for retirement plan selection. The Journal of Human Resources, 48(1):199-235. 
Hampel, F., Ronchetti, E., Rousseeuw, P., and Stahel, W. (1986). Robust statistics: The approach based on influence functions.

Hastings, J. and Mitchell, O. S. (2020). How financial literacy and impatience shape retirement wealth and investment behaviors. Journal of Pension Economics and Finance, 19(1):1-20.

Klapper, L., Lusardi, A., and van Oudheusden, P. (2015). Financial literacy around the world: Insights from the s\&p global financial literacy survey. Technical report, The Global Financial Literacy Excellence Center.

Kotlikoff, L. and Spivak, A. (1981). The family as an incomplete annuities market. Journal of Political Economy, 89(2):372-391.

Kritzer, B., Kay, S., and Sinha, T. (2011). Next generation of individual account pension reforms in latin america. Social Security Bulletin, 71(1):35-76.

Kurach, R. and Kusmierczyk, P. (2017). Can auctions help reduce mandatory pension fund fees? Journal of Pension Economics and Finance, pages 1-30.

Lusardi, A., Michaud, P.-C., and Mitchell, O. S. (2017). Optimal financial knowledge and wealth inequality. Journal of Political Economy, 125(2):431-477.

Murthi, M., Orszag, M., and Orszag, P. (1999). Administrative costs under a decentralized approach to individual accounts: Lessons from the united kingdom. World Bank.

Piketty, T. and Zucman, G. (2015). Wealth and Inheritance in the long run, chapter 15, Wealth and Inheritance in the long run, pages 1303-1366. Elsevier B.V.

Saez, E. and Zucman, G. (2016). Wealth inequality in the united states since 1913: evidence from capitalized income tax data. Quarterly Journal of Economics, 131:519-578.

SBS (2013). Anexo Técnico NÂ․ Metodología aplicable a los cálculos del Aplicativo de Comparación de Comisiones. Superintendencia de Banca, Seguros y AFP.

Tapia, W. and Yermo, J. (2008). Fees in individual account pension systems: A cross-country comparison. OECD Working Papers on Insurance and Private Pensions, (27).

Whitehouse, E. (2001). "Administrative Charges for Funded Pensions: Comparison and Assessment of 13 countries", chapter 2, part 1.6, Insurance and Private Pensions Compendium for Emerging Markets, pages 2-50. Organisation for Economic Co-operation and Development (OECD). 
Appendix 


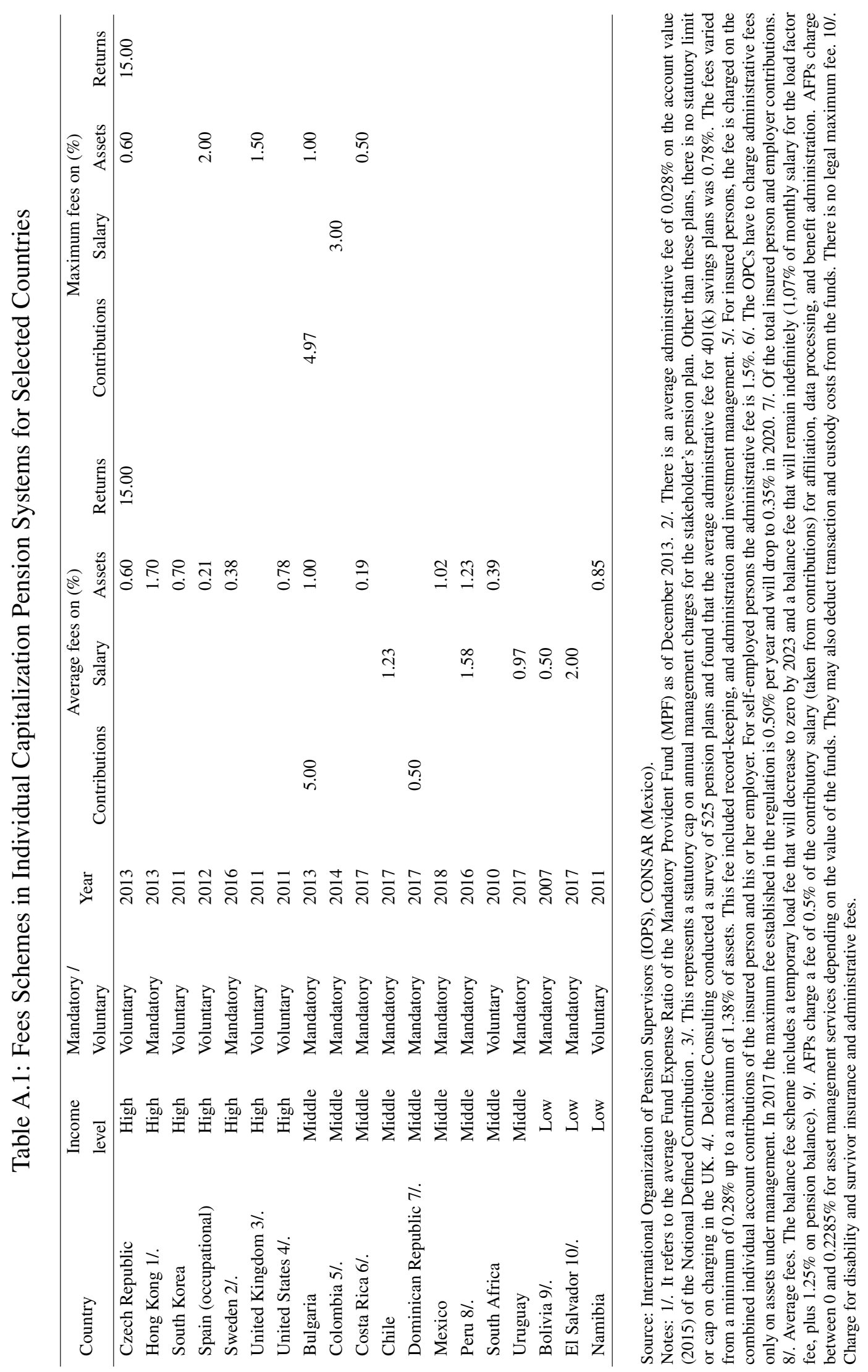


Table A.2: Fees in the Peruvian Private Pension System (December 2016)

\begin{tabular}{lccc}
\hline \multirow{2}{*}{ AFP } & Load factor fee & \multicolumn{2}{c}{ Balance fee scheme } \\
& & $\begin{array}{c}\text { Temporary load factor } \\
\text { fee }\end{array}$ & Balance fee \\
\hline Integra & 1.55 & 1.23 & 1.20 \\
Prima & 1.60 & 1.19 & 1.25 \\
Profuturo & 1.69 & 1.46 & 1.20 \\
Habitat & 1.47 & 0.38 & 1.25 \\
\hline
\end{tabular}

Source: Superintendency of Banking, Insurance and Pension Funds (SBS).

Note: All figures are expressed in percentages. The reform (effective on June 1, 2013) set up the balance fee scheme as the default option, so individuals preferring to remain in the previous load factor fee had to take action. The balance fee scheme includes a temporary load fee that will decrease to zero by 2023 and a balance fee that will remain indefinitely. The only option for new workers enrolling in an AFP after 2013 is the balance fee scheme. See the following regulations for more details: Law $\mathrm{N}^{\circ} 29903$, D. S. $\mathrm{N}^{\circ} 068-2013-\mathrm{EF}$ and Regulations SBS $\mathrm{N}^{\circ}$ 8514-2012, $\mathrm{N}^{\circ}$ 9617-2012, and $\mathrm{N}^{\circ} 2935-2013$.

Table A.3: Sample Selection

\begin{tabular}{lccccc}
\hline & $(1)$ & $(2)$ & $(3)$ & $(4)$ & $(5)$ \\
& Mean & Mean & Mean & Mean & Mean \\
\hline Age & 40.78 & 40.78 & 40.42 & 39.67 & 39.66 \\
Female & 0.37 & 0.37 & 0.36 & 0.35 & 0.35 \\
Income (monthly, in USD) & 704.41 & 704.32 & 690.20 & 766.39 & 765.73 \\
Saving account (monthly, in USD) & $7,685.61$ & $7,685.61$ & $8,458.04$ & $10,788.56$ & $10,769.23$ \\
Months since affiliation & 167.58 & 167.59 & 165.48 & 160.71 & 160.67 \\
Contribution density & 0.43 & 0.43 & 0.47 & 0.64 & 0.64 \\
Fund type 1 (low-risk) & 0.04 & 0.04 & 0.04 & 0.04 & 0.04 \\
Fund type 2 (moderate) & 0.91 & 0.91 & 0.90 & 0.89 & 0.89 \\
Fund type 3 (high-risk) & 0.05 & 0.05 & 0.06 & 0.07 & 0.07 \\
with load factor fee & 0.37 & 0.37 & 0.40 & 0.53 & 0.53 \\
\hline $\mathrm{N}$ & 100,024 & 99,961 & 90,832 & 64,630 & 64,588 \\
\hline
\end{tabular}

Notes: The table shows the main descriptive statistics of our sample compared to the original data and of the samples with the different decisions we make: (1) being enrolled before 2013 and age 21-64, (2) with no missing saving account, (3) with non-zero saving account, (4) with non-missing income information and being current contributor (last registered contribution occurred at least in 2013) and (5) not in the process of retirement. 
Table A.4: Income Annual Growth Rates by Age Group and Income Quintile

\begin{tabular}{lcccccccccc}
\hline \multirow{2}{*}{ Age group } & Q1 & Q2 & Q3 & Q4 & Q5 & Q1 & Q2 & Q3 & Q4 & Q5 \\
\hline $21-25$ & 0.2 & 2.6 & 1.9 & 2.8 & 3.4 & 1.7 & 2.1 & 1.9 & 3.1 & 4.9 \\
$26-30$ & 0.6 & 2.2 & 1.6 & 2.5 & 3.8 & 1.5 & 1.9 & 2.1 & 2.5 & 4.2 \\
$31-35$ & 1.2 & 1.9 & 1.2 & 2.2 & 2.9 & 1.7 & 1.9 & 1.7 & 2.8 & 3.2 \\
$36-40$ & 1.0 & 1.8 & 1.0 & 2.4 & 3.2 & 1.0 & 1.9 & 1.8 & 2.5 & 2.4 \\
$41-45$ & 1.2 & 1.7 & 1.0 & 3.0 & 4.4 & 1.3 & 1.9 & 1.6 & 2.5 & 2.8 \\
$46-50$ & 2.3 & 1.7 & 1.1 & 3.0 & 3.4 & 1.1 & 1.6 & 1.8 & 2.2 & 3.0 \\
$51-55$ & 0.3 & 1.6 & 1.3 & 2.9 & 1.6 & 1.8 & 1.7 & 1.8 & 2.5 & 3.2 \\
$56-60$ & 1.5 & 2.6 & 1.5 & 2.0 & 2.4 & 1.6 & 2.0 & 1.6 & 2.7 & 3.2 \\
$61-64$ & 5.3 & 2.6 & 1.9 & 3.9 & 0.0 & 0.0 & 2.8 & 1.8 & 3.1 & 0.0 \\
\hline
\end{tabular}

Note: The figures indicate the median growth rates (in percentage) of annual income computed with administrative data provided by the SBS for the years 2006 and 2013. The age group correspond to the age of the individuals as of December 2016. 
Table A.5: Mean Differences Among Individuals by Gender and Actual Fee Scheme

\begin{tabular}{|c|c|c|c|c|c|c|c|c|}
\hline \multirow[t]{2}{*}{ Variable } & \multicolumn{2}{|c|}{ Balance fee } & \multicolumn{2}{|c|}{ Load factor fee } & \multicolumn{4}{|c|}{ Mean difference } \\
\hline & $\begin{array}{c}\text { Women } \\
(\mathrm{N}=13,263)\end{array}$ & $\begin{array}{c}\text { Men } \\
(\mathrm{N}=21,004)\end{array}$ & $\begin{array}{c}\text { Women } \\
(\mathrm{N}=9,295)\end{array}$ & $\begin{array}{c}\text { Men } \\
(\mathrm{N}=21,068)\end{array}$ & $\begin{array}{c}\text { Mean } \\
\text { (Women) }\end{array}$ & S.E. & $\begin{array}{l}\text { Mean } \\
(\text { Men })\end{array}$ & S.E. \\
\hline Age & 37.395 & 38.845 & 40.027 & 41.258 & -2.632 & 0.129 & -2.413 & 0.096 \\
\hline Balance not charged with fee (S/. '000) & 12.041 & 16.879 & 42.455 & 55.281 & -30.414 & 0.727 & -38.402 & 1.005 \\
\hline Balance charged with fee (S/. '000) & 3.969 & 5.234 & 0.000 & 0.000 & & & & \\
\hline Total saving balance (S/. '000) & 16.011 & 22.112 & 42.455 & 55.281 & -26.444 & 0.755 & -33.169 & 1.029 \\
\hline 1st quintile & 0.402 & 0.337 & 0.080 & 0.049 & 0.322 & 0.006 & 0.287 & 0.004 \\
\hline 2nd quintile & 0.238 & 0.240 & 0.179 & 0.156 & 0.059 & 0.006 & 0.084 & 0.004 \\
\hline 3th quintile & 0.162 & 0.177 & 0.224 & 0.224 & -0.062 & 0.005 & -0.047 & 0.004 \\
\hline 4th quintile & 0.120 & 0.140 & 0.253 & 0.262 & -0.134 & 0.005 & -0.122 & 0.004 \\
\hline 5 th quintile & 0.077 & 0.105 & 0.264 & 0.309 & -0.186 & 0.005 & -0.203 & 0.004 \\
\hline Monthly labor income (S/.) & $1,551.9$ & $2,013.1$ & $2,770.3$ & $3,462.0$ & $-1,218.5$ & 50.144 & $-1,449.0$ & 73.914 \\
\hline 1st quintile & 0.329 & 0.269 & 0.154 & 0.123 & 0.175 & 0.006 & 0.146 & 0.004 \\
\hline 2nd quintile & 0.263 & 0.205 & 0.203 & 0.149 & 0.060 & 0.006 & 0.056 & 0.004 \\
\hline 3th quintile & 0.177 & 0.207 & 0.199 & 0.201 & -0.023 & 0.005 & 0.006 & 0.004 \\
\hline 4th quintile & 0.125 & 0.189 & 0.203 & 0.245 & -0.079 & 0.005 & -0.055 & 0.004 \\
\hline 5th quintile & 0.107 & 0.130 & 0.241 & 0.282 & -0.133 & 0.005 & -0.152 & 0.004 \\
\hline Contribution density & 0.463 & 0.470 & 0.783 & 0.791 & -0.321 & 0.004 & -0.321 & 0.003 \\
\hline 1st quintile & 0.380 & 0.365 & 0.054 & 0.047 & 0.326 & 0.005 & 0.319 & 0.004 \\
\hline 2nd quintile & 0.261 & 0.257 & 0.152 & 0.146 & 0.108 & 0.006 & 0.112 & 0.004 \\
\hline 3th quintile & 0.153 & 0.172 & 0.224 & 0.234 & -0.071 & 0.005 & -0.061 & 0.004 \\
\hline 4th quintile & 0.107 & 0.116 & 0.269 & 0.283 & -0.162 & 0.005 & -0.167 & 0.004 \\
\hline 5th quintile & 0.100 & 0.090 & 0.300 & 0.292 & -0.201 & 0.005 & -0.202 & 0.004 \\
\hline Self-employed & 0.037 & 0.028 & 0.031 & 0.021 & 0.006 & 0.002 & 0.007 & 0.002 \\
\hline Years enrolled in SPP & 7.719 & 8.506 & 9.872 & 10.710 & -2.154 & 0.082 & -2.204 & 0.059 \\
\hline AFP Integra & 0.416 & 0.375 & 0.427 & 0.397 & -0.011 & 0.007 & -0.022 & 0.005 \\
\hline AFP Profuturo & 0.327 & 0.380 & 0.273 & 0.313 & 0.054 & 0.006 & 0.067 & 0.005 \\
\hline AFP Prima & 0.253 & 0.242 & 0.296 & 0.285 & -0.043 & 0.006 & -0.043 & 0.004 \\
\hline AFP Habitat & 0.004 & 0.003 & 0.004 & 0.005 & 0.000 & 0.001 & -0.002 & 0.001 \\
\hline Fund type 1 (low-risk) & 0.022 & 0.033 & 0.034 & 0.046 & -0.011 & 0.002 & -0.013 & 0.002 \\
\hline Fund type 2 (moderate) & 0.941 & 0.916 & 0.884 & 0.852 & 0.056 & 0.004 & 0.064 & 0.003 \\
\hline Fund type 3 (high-risk) & 0.037 & 0.051 & 0.082 & 0.102 & -0.045 & 0.003 & -0.051 & 0.003 \\
\hline Active portfolio management & 0.041 & 0.056 & 0.092 & 0.113 & -0.051 & 0.003 & -0.057 & 0.003 \\
\hline Have recognition bond & 0.021 & 0.021 & 0.054 & 0.057 & -0.033 & 0.002 & -0.036 & 0.002 \\
\hline
\end{tabular}

Note: The table uses the analyzed sample of SBS administrative registers as of December 2016. The mean differences are computed using twosample t-tests by groups (balance and load factor fee schemes) with unequal variances. The means with finite variance of variables of income, contribution density and pension balance have normal distribution. The test on the equality of proportions is used for dummy variables. 
Table A.6: Mean of Charge Ratios by Age Group and Actual Fee Scheme

\begin{tabular}{lccccc}
\hline \multirow{2}{*}{ Age group } & \multicolumn{2}{c}{ Individuals who chose the load fee } & & \multicolumn{2}{c}{ Individuals assigned to the balance fee } \\
\cline { 2 - 3 } \cline { 5 - 6 } & $\lambda^{l}$ & $\lambda^{m}$ & & $\lambda^{l}$ & $\lambda^{m}$ \\
\hline$[21-25]$ & 0.116 & 0.210 & 0.117 & 0.256 \\
{$[26-30]$} & 0.109 & 0.175 & 0.108 & 0.220 \\
{$[31-35]$} & 0.099 & 0.139 & 0.097 & 0.181 \\
{$[36-40]$} & 0.087 & 0.104 & & 0.084 & 0.141 \\
{$[41-45]$} & 0.073 & 0.073 & 0.074 & 0.107 \\
{$[46-50]$} & 0.059 & 0.047 & 0.064 & 0.077 \\
{$[51-55]$} & 0.047 & 0.030 & 0.052 & 0.053 \\
{$[56-60]$} & 0.033 & 0.017 & 0.039 & 0.034 \\
{$[61-64]$} & 0.014 & 0.007 & 0.018 & 0.014 \\
\hline
\end{tabular}

Note: The age group correspond to the age of the individuals as of December 2016.

Table A.7: Winners and Losers with the Balance and Load Factor Fee by AFP

\begin{tabular}{llccc}
\hline \multirow{2}{*}{ AFP } & & \multicolumn{2}{c}{ Individual's actual fee } & \\
\cline { 3 - 4 } & & $\begin{array}{c}\text { Balance fee } \\
\text { (default option) }\end{array}$ & $\begin{array}{c}\text { Load factor fee } \\
\text { (active choice) }\end{array}$ & Total \\
\hline \multirow{5}{*}{ Habitat } & Balance fee is better & $5(2.0 \%)$ & $53(20.9 \%)$ & 58 \\
& Load factor fee is better & $93(36.6 \%)$ & $103(40.6 \%)$ & 196 \\
& Total & $98(38.6 \%)$ & $156(61.4 \%)$ & 254 \\
\hline \multirow{5}{*}{ Integra } & Balance fee is better & $1,385(5.4 \%)$ & $5,815(22.6 \%)$ & 7,200 \\
& Load factor fee is better & $10,367(40.3 \%)$ & $8,163(31.7 \%)$ & 18,530 \\
& Total & $11,752(45.7 \%)$ & $13,978(54.3 \%)$ & 25,730 \\
\hline \multirow{3}{*}{ Prima } & Balance fee is better & $772(4.4 \%)$ & $3,360(19.3 \%)$ & 4,132 \\
& Load factor fee is better & $6,687(38.5 \%)$ & $6,547(37.7 \%)$ & 13,234 \\
& Total & $7,459(43.0 \%)$ & $9,907(57.0 \%)$ & 17,366 \\
\hline \multirow{3}{*}{ Profuturo } & Load factor fee is better & $9,600(45.2 \%)$ & $5,426(25.5 \%)$ & 15,026 \\
& Total & $11,042(52.0 \%)$ & $10,196(48.0 \%)$ & 21,238 \\
\hline
\end{tabular}

Note: Figures in parenthesis report the percentage of individuals in each cell with respect to the total by AFP. 
Table A.8: Losses and Gains by Actual Fee Scheme and Income Quintiles

\begin{tabular}{llrrrrrr}
\hline Type of choice & Measure & Q1 & Q2 & Q3 & Q4 & Q5 & Total \\
\hline Balance fee & \% individuals losing & 87.2 & 91.4 & 89.5 & 87.9 & 82.5 & 88.1 \\
(default option) & \% individuals gaining & 12.8 & 8.6 & 10.5 & 12.1 & 17.5 & 11.9 \\
& avg \% change in balance (for those losing) & -6.9 & -7.6 & -7.3 & -7.1 & -6.7 & -7.1 \\
& avg \% change in balance (for those gaining) & 0.8 & 0.6 & 0.7 & 0.8 & 0.8 & 0.8 \\
& avg \% change in pension balance (for all) & -5.9 & -6.9 & -6.4 & -6.1 & -5.4 & -6.2 \\
\hline Load fee & \% individuals losing & 45.3 & 41.3 & 39.8 & 40.6 & 39.4 & 40.9 \\
(active choice) & \% individuals gaining & 54.7 & 58.7 & 60.2 & 59.4 & 60.6 & 59.1 \\
& avg \% change in balance (for those losing) & -1.0 & -1.0 & -1.1 & -1.2 & -1.3 & -1.1 \\
& avg \% change in balance (for those gaining) & 3.4 & 3.5 & 3.7 & 3.9 & 3.8 & 3.7 \\
& avg \% change in pension balance (for all) & 1.4 & 1.6 & 1.8 & 1.8 & 1.8 & 1.7 \\
\hline \multirow{2}{*}{ Total } & 72.7 & 68.3 & 63.0 & 59.3 & 52.0 & 63.1 \\
& \% individuals losing & 27.3 & 31.7 & 37.0 & 40.7 & 48.0 & 36.9 \\
& \% individuals gaining & -5.6 & -5.7 & -5.2 & -4.7 & -3.8 & -5.1 \\
& avg \% change in balance (for those losing) & 2.6 & 3.1 & 3.3 & 3.5 & 3.5 & 3.3 \\
& avg \% change in balance (for those gaining) & 2.5 & -2.3 \\
& avg \% change in pension balance (for all) & -3.4 & -2.9 & -2.0 & -1.3 & -0.3 & -2.0 \\
\hline
\end{tabular}

Table A.9: Losses and Gains by Actual Fee Scheme and Contribution Density Quintiles

\begin{tabular}{|c|c|c|c|c|c|c|c|}
\hline Type of choice & Measure & Q1 & Q2 & Q3 & Q4 & Q5 & Total \\
\hline Balance fee & $\%$ individuals losing & 90.8 & 92.8 & 89.8 & 87.6 & 61.9 & 88.1 \\
\hline \multirow[t]{4}{*}{ (default option) } & $\%$ individuals gaining & 9.2 & 7.2 & 10.2 & 12.4 & 38.1 & 11.9 \\
\hline & avg $\%$ change in balance (for those losing) & -7.5 & -7.8 & -7.3 & -6.9 & -2.5 & -7.1 \\
\hline & avg $\%$ change in balance (for those gaining) & 1.0 & 0.9 & 0.8 & 0.7 & 0.4 & 0.8 \\
\hline & avg $\%$ change in pension balance (for all) & -6.7 & -7.2 & -6.5 & -5.9 & -1.4 & -6.2 \\
\hline \multirow{5}{*}{$\begin{array}{l}\text { Load fee } \\
\text { (active choice) }\end{array}$} & $\%$ individuals losing & 36.7 & 29.4 & 29.8 & 28.7 & 67.5 & 40.9 \\
\hline & $\%$ individuals gaining & 63.3 & 70.6 & 70.2 & 71.3 & 32.5 & 59.1 \\
\hline & avg $\%$ change in balance (for those losing) & -1.0 & -1.2 & -1.2 & -1.3 & -1.1 & -1.1 \\
\hline & avg $\%$ change in balance (for those gaining) & 4.5 & 4.1 & 3.9 & 4.1 & 1.9 & 3.7 \\
\hline & avg $\%$ change in pension balance (for all) & 2.5 & 2.6 & 2.4 & 2.6 & -0.1 & 1.7 \\
\hline \multirow[t]{5}{*}{ Total } & $\%$ individuals losing & 83.7 & 67.9 & 53.2 & 44.3 & 66.3 & 63.1 \\
\hline & $\%$ individuals gaining & 16.3 & 32.1 & 46.8 & 55.7 & 33.7 & 36.9 \\
\hline & avg $\%$ change in balance (for those losing) & -7.1 & -6.7 & -5.2 & -4.2 & -1.4 & -5.1 \\
\hline & avg $\%$ change in balance (for those gaining) & 2.8 & 3.7 & 3.6 & 3.9 & 1.5 & 3.3 \\
\hline & avg $\%$ change in pension balance (for all) & -5.5 & -3.3 & -1.1 & 0.3 & -0.4 & -2.0 \\
\hline
\end{tabular}


Table A.10: Losses and Gains by Actual Fee Scheme and Balance Quintiles

\begin{tabular}{llrrrrrr}
\hline Type of choice & Measure & Q1 & Q2 & Q3 & Q4 & Q5 & Total \\
\hline Balance fee & \% individuals losing & 89.1 & 90.4 & 88.1 & 85.9 & 82.1 & 88.1 \\
(default option) & \% individuals gaining & 10.9 & 9.6 & 11.9 & 14.1 & 17.9 & 11.9 \\
& avg \% change in balance (for those losing) & -7.3 & -7.4 & -7.2 & -6.7 & -6.2 & -7.1 \\
& avg \% change in balance (for those gaining) & 1.2 & 0.7 & 0.5 & 0.5 & 0.5 & 0.8 \\
& avg \% change in pension balance (for all) & -6.4 & -6.6 & -6.3 & -5.7 & -5.0 & -6.2 \\
\hline Load fee & \% individuals losing & 46.4 & 43.9 & 40.7 & 39.6 & 39.3 & 40.9 \\
(active choice) & \% individuals gaining & 53.6 & 56.1 & 59.3 & 60.4 & 60.7 & 59.1 \\
& avg \% change in balance (for those losing) & -1.8 & -1.4 & -1.1 & -1.0 & -1.0 & -1.1 \\
& avg \% change in balance (for those gaining) & 4.2 & 3.7 & 3.7 & 3.7 & 3.6 & 3.7 \\
& avg \% change in pension balance (for all) & 1.4 & 1.5 & 1.8 & 1.8 & 1.8 & 1.7 \\
\hline \multirow{2}{*}{ Total } & 82.2 & 70.1 & 59.9 & 54.1 & 49.1 & 63.1 \\
& \% individuals losing & 17.8 & 29.9 & 40.1 & 45.9 & 50.9 & 36.9 \\
& \% individuals gaining & -6.8 & -5.8 & -4.7 & -3.8 & -3.0 & -5.1 \\
& avg \% change in balance (for those losing) & 2.7 & 3.2 & 3.3 & 3.4 & 3.4 & 3.3 \\
& avg \% change in balance (for those gaining) & 2.1 & -3.1 & -1.5 & -0.5 & 0.3 & -2.0 \\
\hline
\end{tabular}


Table A.11: Probability To Be Better Off with the Load Factor Fee

\begin{tabular}{|c|c|c|c|c|}
\hline & \multicolumn{2}{|c|}{$\begin{array}{l}\text { Prob. Load factor fee is better } \\
\text { (among those choosing the load } \\
\text { fee) }\end{array}$} & \multicolumn{2}{|c|}{$\begin{array}{l}\text { Prob. Load factor fee is better } \\
\text { (among those assigned to the } \\
\text { balance fee) }\end{array}$} \\
\hline & Coef. & S.E. & Coef. & S.E. \\
\hline Male & $0.0064 * * *$ & $(0.0014)$ & 0.0004 & $(0.0006)$ \\
\hline Age & $-0.0064 * * *$ & $(0.0015)$ & $-0.0032 * * *$ & $(0.0002)$ \\
\hline Contribution density & $0.0061 * * *$ & $(0.0016)$ & $-0.0041 * * *$ & $(0.0012)$ \\
\hline Pension balance - 2nd quintile & $-0.0097 * *$ & $(0.0040)$ & $-0.0021 * *$ & $(0.0011)$ \\
\hline Pension balance - 3th quintile & $-0.0419 * * *$ & $(0.0126)$ & $-0.0059 * * *$ & $(0.0018)$ \\
\hline Pension balance - 4th quintile & $-0.0959 * * *$ & $(0.0241)$ & $-0.0080 * * *$ & $(0.0024)$ \\
\hline Pension balance - 5th quintile & $-0.2085^{* * *}$ & $(0.0418)$ & $-0.0055^{* *}$ & $(0.0025)$ \\
\hline Income - 2nd quintile & -0.0005 & $(0.0005)$ & $0.0049 * * *$ & $(0.0006)$ \\
\hline Income - 3 th quintile & 0.0002 & $(0.0003)$ & $0.0038 * * *$ & $(0.0006)$ \\
\hline Income - 4th quintile & $-0.0068 * * *$ & $(0.0020)$ & $0.0017 * *$ & $(0.0007)$ \\
\hline Income - 5th quintile & $-0.0052 * * *$ & $(0.0018)$ & $-0.0038 * * *$ & $(0.0014)$ \\
\hline Self-employed & -0.0001 & $(0.0007)$ & $0.0020^{*}$ & $(0.0011)$ \\
\hline Years enrolled in SPP & $-0.0002 * * *$ & $(0.0000)$ & $0.0004 * * *$ & $(0.0001)$ \\
\hline AFP Profuturo & $-0.1439 * * *$ & $(0.0136)$ & $-0.0035^{* * *}$ & $(0.0007)$ \\
\hline AFP Prima & 0.0002 & $(0.0003)$ & 0.0002 & $(0.0007)$ \\
\hline AFP Habitat & 0.0005 & $(0.0008)$ & $0.0062 * * *$ & $(0.0005)$ \\
\hline $\begin{array}{l}\text { Active portfolio management } \\
\text { Constant }\end{array}$ & 0.0001 & $(0.0003)$ & $-0.0032 * *$ & $(0.0013)$ \\
\hline $\mathrm{R} 2$ & 0.9489 & & 0.5722 & \\
\hline $\mathrm{N}$ & 34237 & & 30351 & \\
\hline
\end{tabular}

Note: All regressions include regional fixed effects. The dependent variable of these models equals one if $\lambda^{l}<\lambda^{m}$ and zero otherwise. The reference category for the balance and income quintiles is the first quintile, for the self-employed is employee, and for the fund administrators is AFP Integra. Robust standard errors are in parentheses. ${ }^{*} \mathrm{p}<0.10,{ }^{* *} \mathrm{p}<0.05, * * * \mathrm{p}<0.01$. 
Figure A.1: Mean Predicted Conditional Probability that Load Factor Fee Scheme is Better

(a) Probability by Age and Actual Fee Scheme

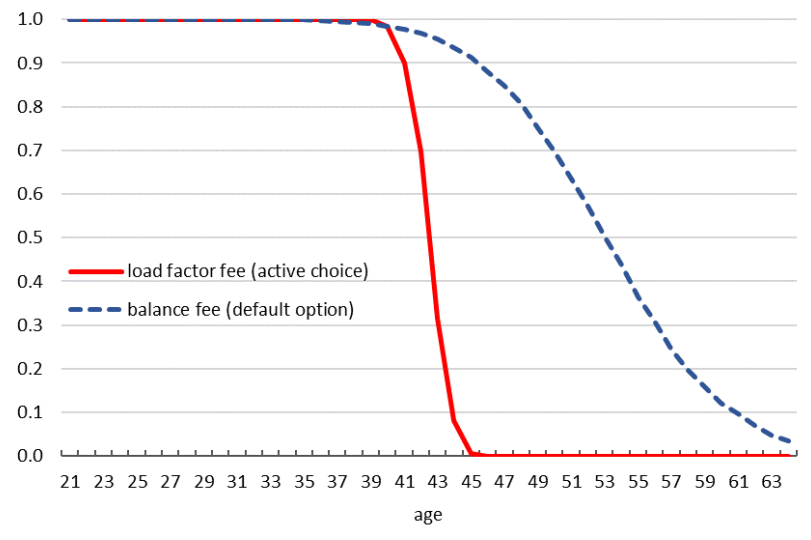

(b) Probability by Income Ventiles and Actual Fee Scheme

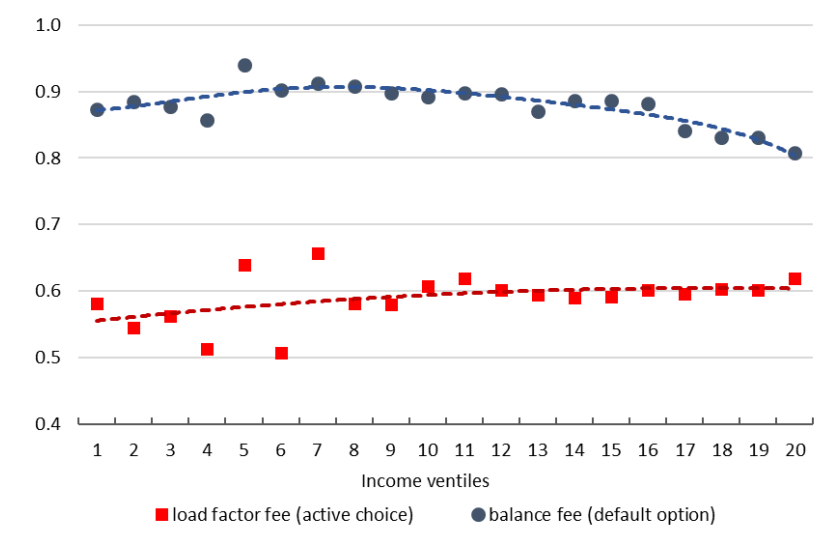

(c) Probability by Balance Ventiles and Actual Fee Scheme

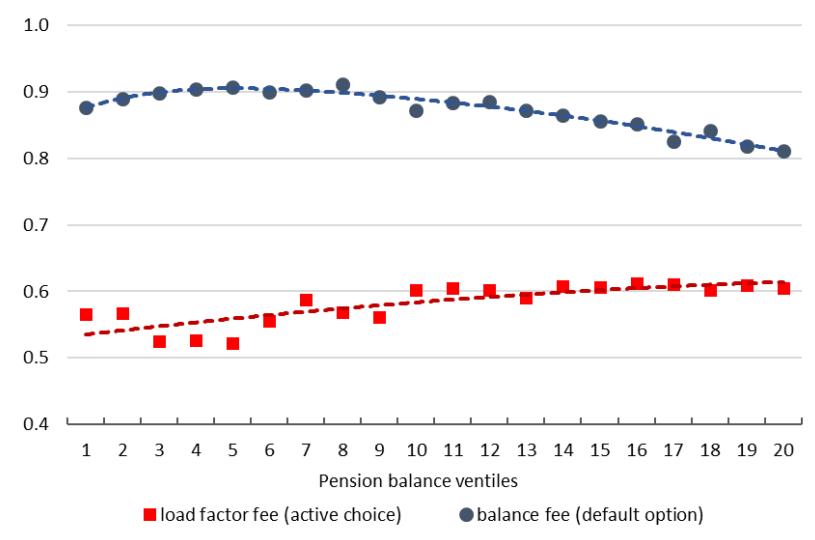

Note: The predicted probabilities are based on estimations displayed in Table A.11. 


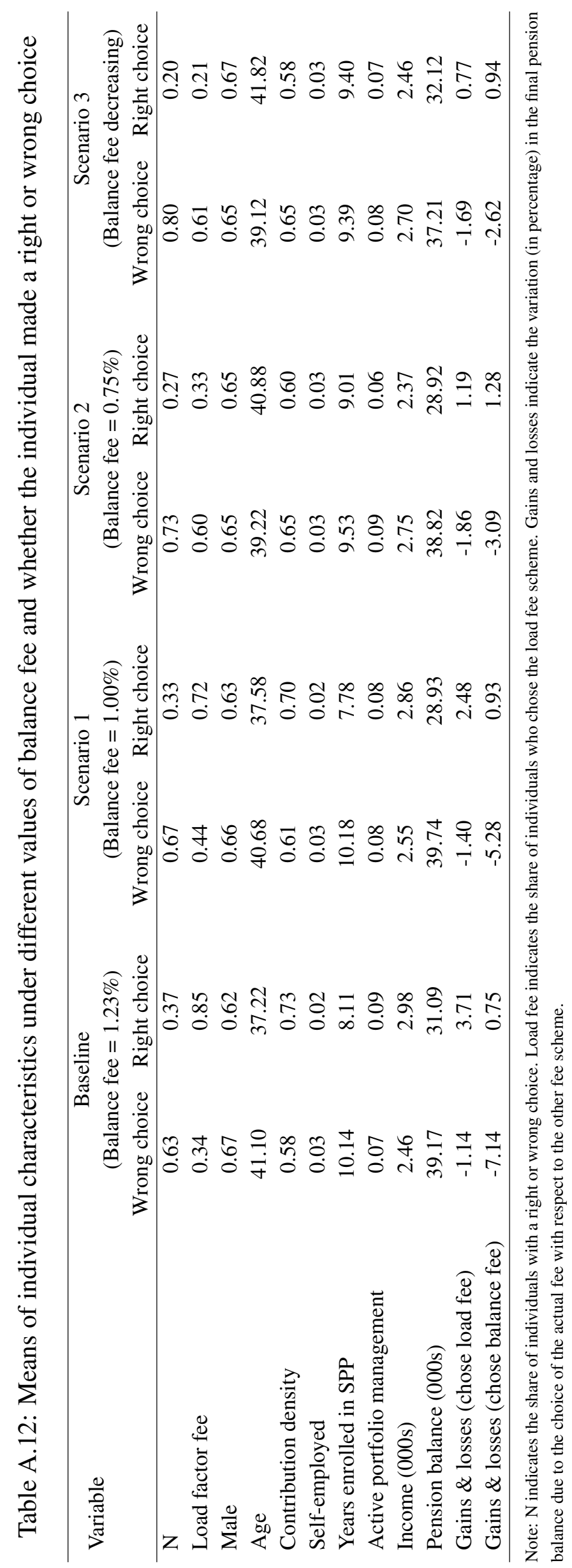


Figure A.2: Cumulative of Gains and Losses with a Balance Fee of 1\%

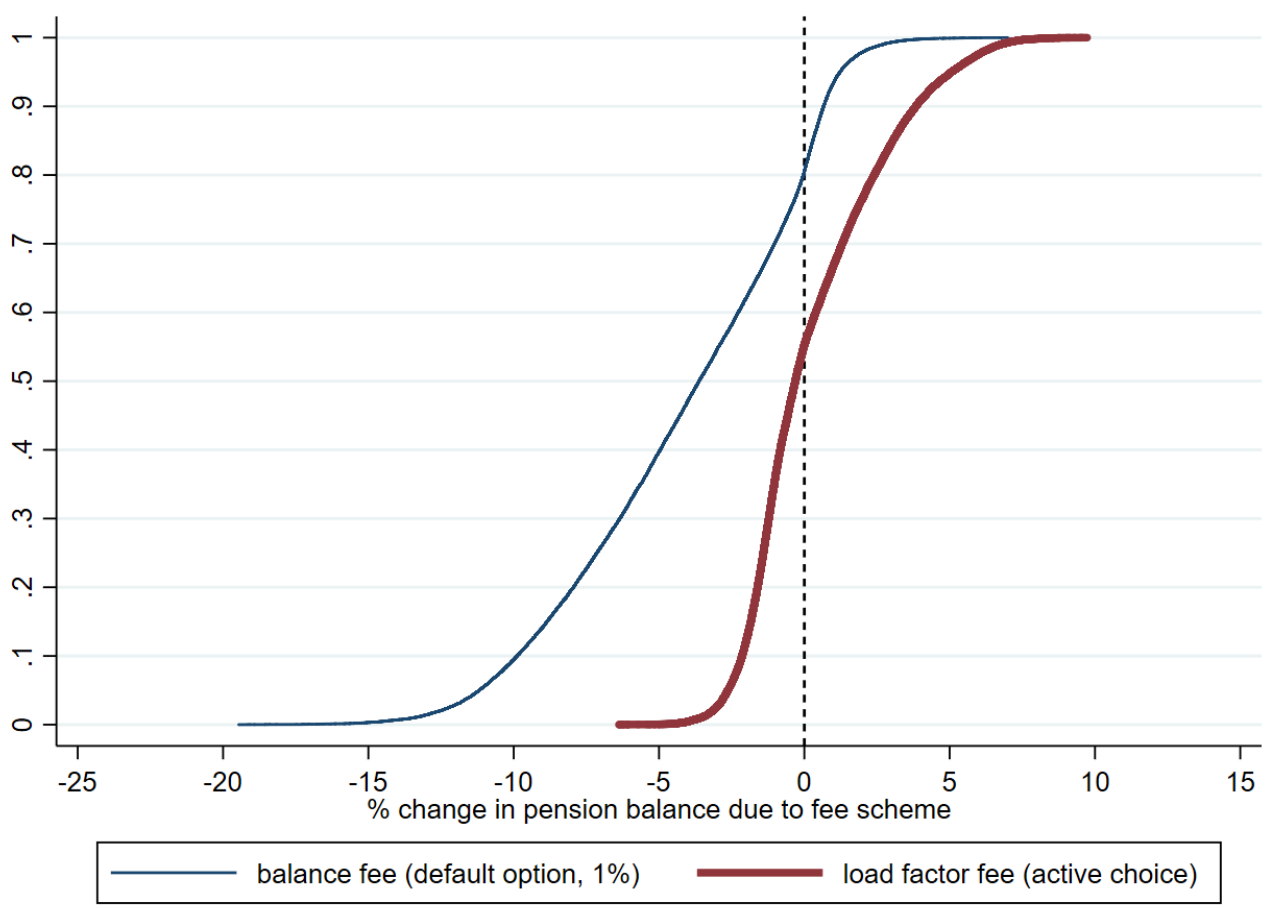

Figure A.3: Cumulative of Gains and Losses with a Balance Fee of 0.75\%

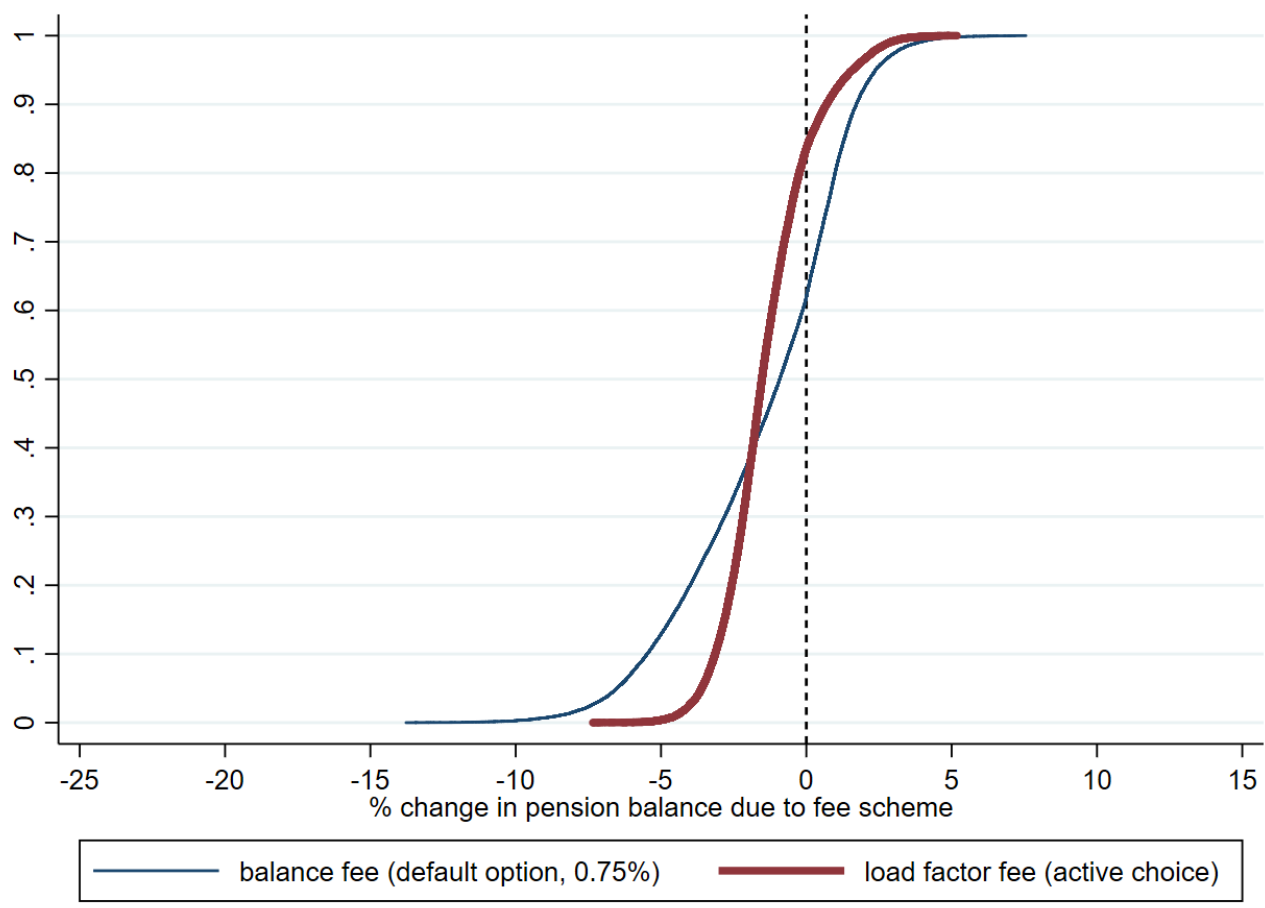


Figure A.4: Cumulative of Gains and Losses with a decreasing Balance Fee

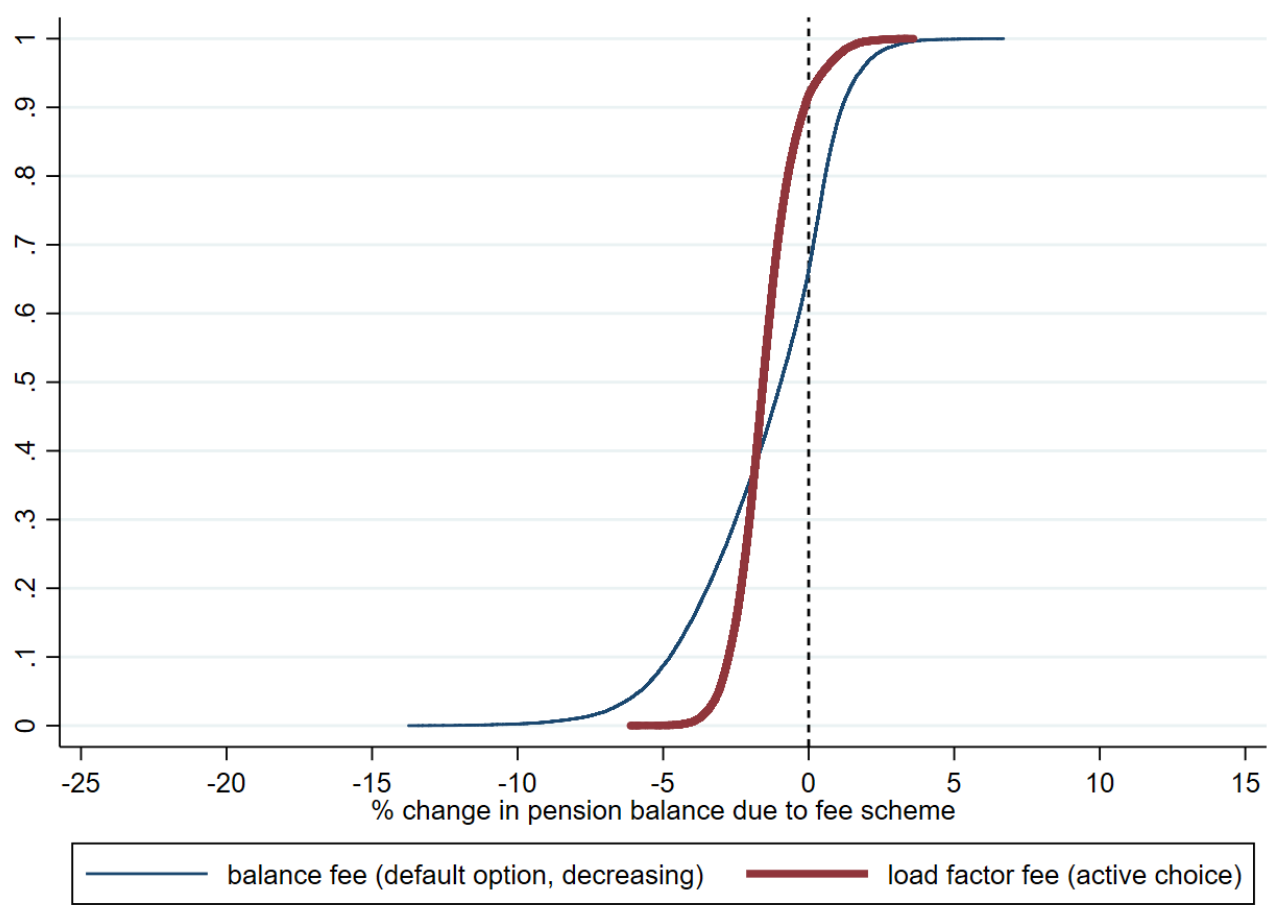




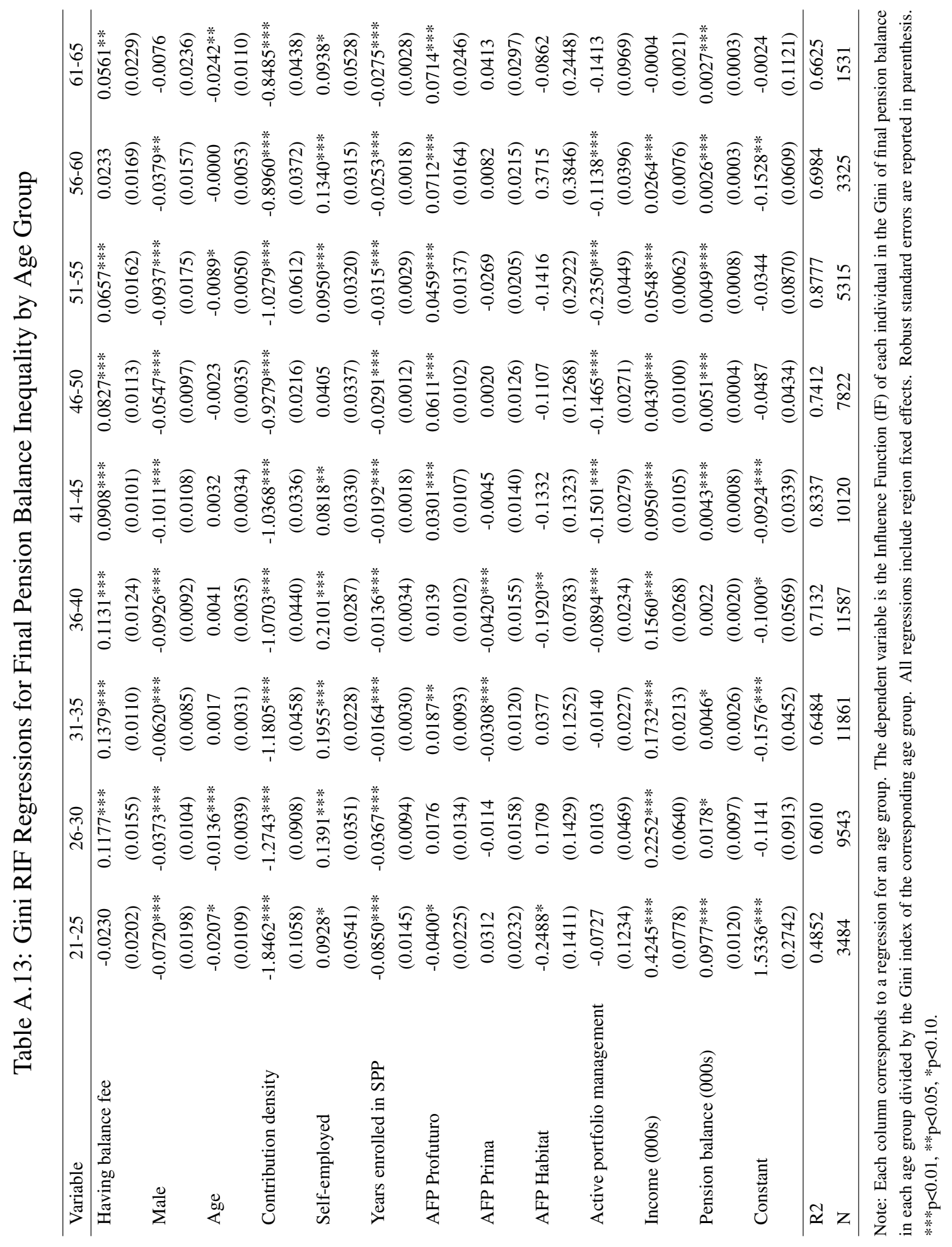


Figure A.5: Share of individuals with a good choice of fees by discount interest rate and distinctive scenarios

(a) Share of individuals with good choice of fees among those who chose the load fee scheme

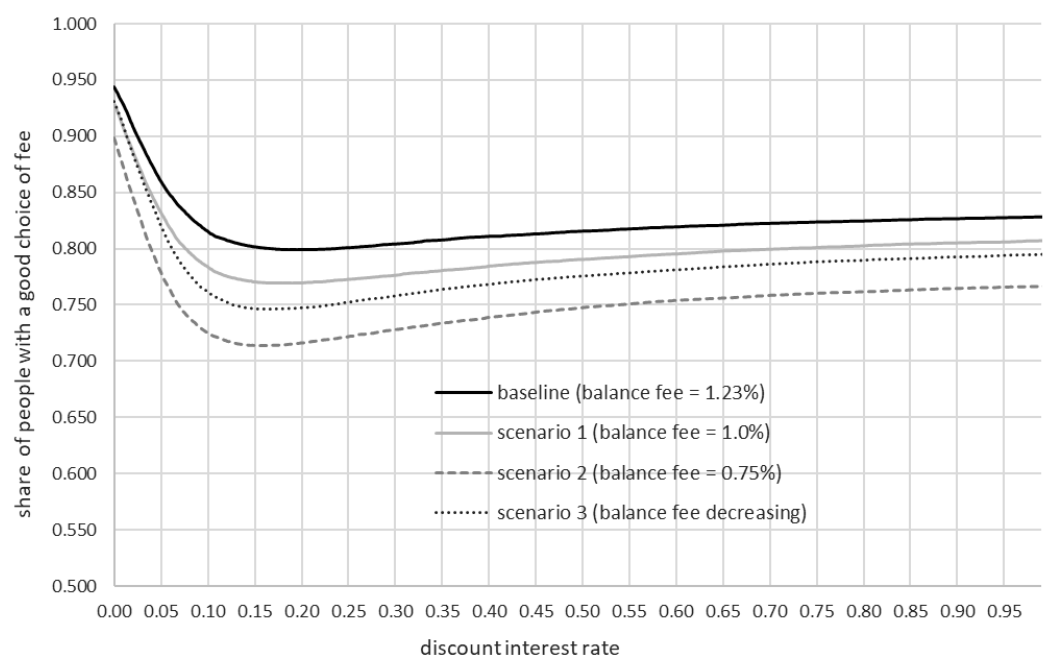

(b) Share of individuals with good choice of fees among those who have the balance fee scheme

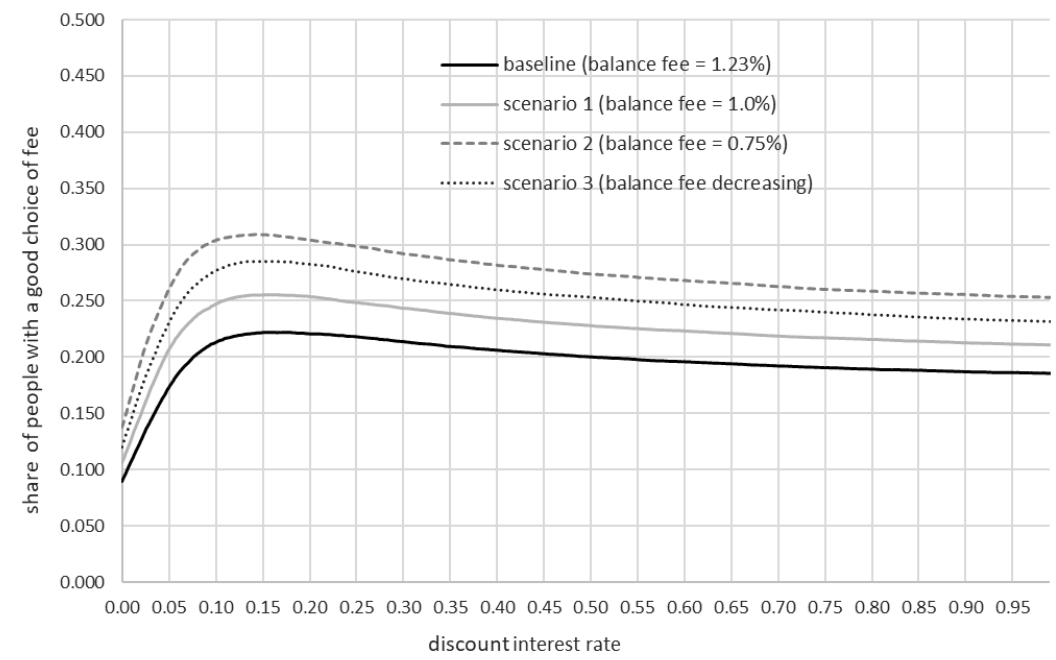

Note: The graphs plot the share of individuals whose actual fee scheme corresponds to the one attaining the largest indirect utility computed with different values of discount interest rates and considering distinctive scenarios of pension fund simulations. In the upper graph, this share is computed in the sample of individuals who chose the load factor fee scheme, while in the bottom graph the share is computed among the individuals who have the balance fee scheme. 


\section{FINDING THE OPTIMAL CHOICE}

We rewrite equations (9) and 10 as follows:

$$
\begin{aligned}
& E U=\sum_{t=0}^{D-x} p_{x_{t}} \beta^{t} \frac{C_{t}^{1-\gamma}}{1-\gamma} \\
& \sum_{t=0}^{D-x} p_{x_{t}} C_{t} R^{-t}=\sum_{t=0}^{65-x-1}\left[w_{t}\left(1-c_{t}-a_{1 t}\right) R^{-t}\right]+ \\
& \sum_{t=65-x}^{D-x}\left[\frac{S_{0}\left(1+r_{t}\right)^{65-x-1}+\sum_{t=0}^{65-x-1} p_{t} c_{t} w_{t}\left(1+r_{t}\right)^{65-x-1-t}}{A_{65}}\right] R^{-t} \\
& \sum_{t=0}^{D-x} p_{x_{t}} C_{t} R^{-t}=\sum_{t=0}^{65-x-1}\left[w_{t}\left(1-c_{t}-a_{3 t}\right) R^{-t}\right]+ \\
& \sum_{t=65-x}^{D-x}\left[\frac{S_{0}\left(1+r_{t}\right)^{65-x-1}+\sum_{t=0}^{65-x-1} p_{t} c_{t} w_{t}\left(1+r_{t}\right)^{65-x-1-t}\left(1-a_{2 t}\right)^{65-x-1-t}}{A_{65}}\right] R^{-t}
\end{aligned}
$$

Equations 11 and 12 correspond to the budget constraints when the individual chooses the load factor fee or the balance fee, respectively. In both cases, the discounted consumption plan must be financed with all resources earned from labor between age $x$ and retirement age assumed in 65 , and with the resources from pensions obtained in old-age until death. We assume that the individual receives a life annuity pension that is computed as the total savings divided by the annuity price $A_{65}$ at age 65 . Note how load factor charges $\left(a_{1 t}, a_{3 t}\right)$ affect labor income streams whereas the balance charge $\left(a_{2 t}\right)$ affects pension resources. $S_{0}$ stands for the initial pension balance in period 0 .

For the load factor fee, maximization of equation 11 subject to equation 12 leads to the following consumption plan:

$$
C_{t}^{*}=\frac{W_{0}^{l}}{\sum_{t=0}^{D-65} p_{x_{t}} \beta^{\frac{t}{\gamma}} R^{\frac{t}{\gamma}-t}}
$$

where $W_{0}^{l}$ summarizes all resources from labor and pension savings described in the righthand side of the budget constraint.

In the case of the balance fee, maximizing equation 11 subject to equation 13 leads to: 


$$
C_{t}^{*}=\frac{W_{0}^{m}}{\sum_{t=0}^{D-65} p_{x_{t}} \beta^{\frac{t}{\gamma}} R^{\frac{t}{\gamma}-t}}
$$

where $W_{0}^{m}$ equals the right-hand side of the corresponding budget constraint.

Once the optimal consumption plans are found for each fee, we obtain the indirect utilities as functions of the initial balance as follows:

$$
\begin{aligned}
& V=\sum_{t=0}^{D-65} p_{x_{t}} \beta^{t}\left[\frac{W_{0}^{l}}{\left.\frac{p_{x_{t}} \beta^{\frac{t}{\gamma}} R^{\frac{t}{\gamma}-t}}{1-\gamma}\right]^{1-\gamma}}\right. \\
& H=\sum_{t=0}^{D-65} p_{x_{t}} \beta^{t}\left[\frac{W_{0}^{m}}{\frac{p_{x_{t}} \beta^{\frac{t}{\gamma}} R^{\frac{t}{\gamma}-t}}{1-\gamma}}\right]^{1-\gamma}
\end{aligned}
$$

where $V$ and $H$ are the indirect utilities for the load factor and balance fees, respectively. We compare the value of the utilities as:

$$
\frac{V}{H}=\left[\frac{W_{0}^{l}}{W_{0}^{m}}\right]^{1-\gamma}
$$

and it suffices that $W_{0}^{l}>W_{0}^{m}$ to establish that the load factor fee is better than the balance fee. 


